\title{
Temperate agroforestry systems provide greater pollination service than monoculture
}

Article

Accepted Version

Creative Commons: Attribution-Noncommercial-No Derivative Works 4.0

Varah, A., Jones, H., Smith, J. and Potts, S. G. (2020)

Temperate agroforestry systems provide greater pollination service than monoculture. Agriculture, Ecosystems and Environment, 301. 107031. ISSN 0167-8809 doi: https://doi.org/10.1016/j.agee.2020.107031 Available at https://centaur.reading.ac.uk/91560/

It is advisable to refer to the publisher's version if you intend to cite from the work. See Guidance on citing.

To link to this article DOI: http://dx.doi.org/10.1016/j.agee.2020.107031

Publisher: Elsevier

All outputs in CentAUR are protected by Intellectual Property Rights law, including copyright law. Copyright and IPR is retained by the creators or other copyright holders. Terms and conditions for use of this material are defined in the End User Agreement.

www.reading.ac.uk/centaur 
Central Archive at the University of Reading

Reading's research outputs online 


\section{Temperate agroforestry systems provide greater pollination service than}

\section{2 monoculture}

3 Alexa Varah ${ }^{a, 1} *$, Hannah Jones ${ }^{a}$, Jo Smith ${ }^{b}$ and Simon G Potts ${ }^{a}$

$4{ }^{a}$ Centre for Agri-Environmental Research, School of Agriculture, Policy and Development, University of Reading, Reading

5 RG6 6AR, United Kingdom

6 b The Organic Research Centre, Elm Farm, Hamstead Marshall, Newbury, Berkshire RG20 OHR, United Kingdom.

$7 \quad *$ Corresponding author: a.varah@nhm.ac.uk

\footnotetext{
${ }^{1}$ Present address: Natural History Museum, Cromwell Road, London SW7 5BD United Kingdom Email: a.varah@nhm.ac.uk
} 


\section{Abstract}

Insect pollination is a globally important ecosystem service, contributing to crop yields, production stability and the maintenance of wild plant populations. Ironically, agriculture is one of the major global drivers of wild insect pollinator decline. At the same time, increasing human population is driving ever greater demands on crop production. Agroforestry (AF) - a more diverse farming system integrating woody and agricultural crops - can theoretically reconcile high production with provision of ecosystem services such as pollination. However, empirical studies of pollination in temperate AF systems are almost entirely lacking. We sought to fill this knowledge gap by assessing whether AF can provide increased pollination service compared to monoculture (MC) systems. Six UK sites, each containing an AF and a MC system, were studied over three years. Wild pollinator abundance and diversity were used as proxies for the magnitude and stability, respectively, of the pollinating community. We also directly measured pollination service as seed set in a wild plant phytometer. We found that temperate AF systems can provide greater pollination service than MC: AF treatments had twice as many solitary bees and hoverflies, and in arable systems 2.4 times more bumblebees, than MC treatments. AF also had 4.5 times more seed set compared to $M C$ in one of the two years. At $40 \%$ of site-by-year sampling units, species richness of solitary bees was on average 10.5 times higher in AF treatments. This provides evidence in favour of the expectation that AF systems can support higher pollinator richness, and therefore greater potential stability, of pollination service. For the other sampling units, and for bumblebees (Bombus spp.), there was no treatment effect on species richness. Further work is needed to investigate the effect of AF on species richness and its mechanistic basis. Our results also highlight the importance of AF system design, ensuring that ecosystem services outcomes are explicitly planned at the design stage. We suggest that AF has a role to play in improving the sustainability of modern farming and in mitigating the ongoing loss of wild pollinating insects, which is strongly driven by prevailing agricultural practices.

Keywords: Agroforestry, pollination service, bumblebee, hoverfly, solitary bee, abundance, richness 


\section{Introduction}

Intensive agriculture is one of the primary causes of biodiversity loss globally (Foley et al., 2005; IPBES, 2019; Newbold et al., 2015); ironically, it is also heavily reliant on biodiversity to support the ecosystem functions and services that underpin food production (Dainese et al., 2019; Garibaldi et al., 2013). Of these, pollination service has received particular attention as $35 \%$ of global crop production volume is dependent on insect pollination to some extent (Klein et al., 2007), and pollinators affect both the quantity (Castle et al., 2019; Fijen et al., 2018) and quality (Garratt et al., 2014; Klatt et al., 2013) of food produced. Despite widespread awareness of their importance, wild pollinating insect abundance and diversity continue to decline in some regions of the world (Potts et al., 2016, 2010; Powney et al., 2019). These pollinator declines, as for wider biodiversity, are driven in large part by agricultural intensification (Goulson et al., 2015; Grab et al., 2019). There is consensus that agriculture-related factors (habitat loss, and pollutants such as synthetic pesticides and fertilisers) are amongst the major drivers of insect declines worldwide (Sánchez-Bayo and Wyckhuys, 2019; Vanbergen and the IPI, 2013). These reductions in pollinator abundance and diversity are thought to have negative effects on global food production and wild plant pollination (Grab et al., 2019; Potts et al., 2016): global trends are already showing lower mean relative yields and lower yield growth in crops with greater pollination dependence (Deguines et al., 2014; Garibaldi et al., 2011a).

Efforts to mitigate loss of biodiversity in farmed land focus largely on increasing wild plant diversity as it is known that this can benefit wild pollinating insects (Isbell et al., 2017; Kovács-Hostyánszki et al., 2017). In Europe, practical interventions to increase floral resources and plant structural diversity on farmland have predominantly been encouraged through agri-environment schemes introduced via the Common Agricultural Policy. These have had some positive effects on wild bees (Scheper et al., 2013) but have less success at increasing biodiversity in field centres (Batáry et al., 2015) and, overall, numbers of insect pollinators continue to decline in many areas of the world (Goulson et al., 2015; Potts et al., 2016; Powney et al., 2019). 
The trade-off with biodiversity loss has been high yields; however, it is becoming evident that the yield benefits of intensive agriculture are beginning to plateau and, in some countries, are even falling (Lin and Huybers, 2012; Ray et al., 2012). At the same time, global population and thus food demand are increasing. These facts, combined with the continuing degradation of agroecosystems and the realisation that farmed land is no longer providing the ecosystem services it once did, have led to calls for more environmentally sustainable, yet still intensive, farming practices (Garibaldi et al., 2016; Isbell et al., 2017; Pretty et al., 2018). These recognise the key role that biodiversity plays in food production (Dainese et al., 2019; IPBES, 2019; Rockström et al., 2017). Research is needed to ascertain the implications for pollinators of these alternative farming practices (Dicks et al., 2013).

$\mathrm{AF}$ is one such practice, integrating woody species with crop or livestock species. In modern AF systems, crops/livestock are grown in alleys between tree rows which can produce timber, fruit, nuts or any other woody product (Smith et al., 2012). It thus has inherently greater plant diversity per unit area (in terms of both crops and wild plants, such as those in the tree row understorey). Furthermore, this increased plant diversity extends throughout the field rather than being confined to field margins. Thus, in intensively-farmed landscapes, AF systems could benefit biodiversity by increasing the permeability of the agricultural matrix (Vandermeer and Perfecto, 2007). Indeed, improving habitat in the cropped area has been shown to be of greater relative importance in mitigating biodiversity loss than improving habitat in field margins (Butler et al., 2009). AF systems also increase edge density in agroecosystems, which has been shown to increase insect pollinator abundance and promote ecosystem service provision (Martin et al., 2019).

The interactions created in AF systems, when carefully managed, are theorised to provide numerous benefits (Jose, 2009; Kay et al., 2018; Kuyah et al., 2017) for example through improved provision of nesting, shelter and foraging resources (Kay et al., 2019; Nicholls and Altieri, 2013; Persson et al., 2015). Foraging resources, in particular, directly regulate bee populations (Roulston and Goodell, 2011), and bee populations also respond positively to linear elements (Kallioniemi et 

al., 2017). Despite its proposed benefits, AF remains understudied in temperate systems and implementation has been low; due, in part, to lack of data demonstrating the economic and environmental outcomes of these systems (Meyer, 2012; Rhodes et al., 2018; Valdivia et al., 2012). In the tropics, there is evidence of improved pollinator abundance and diversity in AF systems (Briggs et al., 2013; Hass et al., 2018; Hoehn et al., 2012) but applied work on pollination in temperate AF systems is almost non-existent: before this study (for preliminary results see Varah et al. (2013)) there was just one case study which found increased abundance of airborne arthropods in an AF system (Peng et al., 1993).

To help fill this knowledge gap, we aimed to assess whether AF can benefit wild pollinators. To do this we compared wild insect pollinator abundance, species richness, and pollination service in six paired organic AF and MC systems in the United Kingdom (UK). We focused on wild insect pollinators (we chose bumblebees (Bombus spp.), solitary bees, and hoverflies (Syrphidae)) because (a) the majority of pollination service is provided by wild, rather than managed, pollinating species (Breeze et al., 2011; Garibaldi et al., 2013; Smith et al., 2011), and (b) although honey bees are important crop pollinators, their abundance is primarily driven by beekeeper decision-making rather than environmental factors. We assumed that a greater abundance and/or greater diversity of pollinating insects results in improved pollination service; either in terms of the magnitude of the service, which has been linked more closely to pollinator abundance (Castle et al., 2019; Garibaldi et al., 2013; Winfree et al., 2015; Woodcock et al., 2019), or the stability of the service, linked more closely to pollinator diversity (Garibaldi et al., 2011b; Hoehn et al., 2008; Winfree et al., 2018).

We predicted:

(1) Higher pollinator abundance in AF than MC.

(2) Higher pollinator species richness in AF than MC.

(3) Higher pollination service in AF than MC. 


\section{Methods}

111

112

113

114

115

116

117

118

119

120

121

122

\subsection{Study sites and experimental design}

The effect of AF systems on pollination service was assessed in the UK using paired fields, one of which had an agricultural crop plus a tree crop (the AF treatment), the other of which had only the agricultural crop (the MC treatment). In this way we set up six sites, each with an AF system paired with an 'equivalent' agricultural MC. No suitable forestry MC (or other woody species MCs) were available, so comparison of AF vs tree MC systems was not possible. Sites were chosen based on several biological and logistical considerations (Appendix A). The sites encompassed a range of landscape contexts, regions and AF types (Table A.1), allowing broad conclusions to be drawn about UK AF systems. Both arable AF (silvoarable) and pasture AF (silvopasture) sites were included. A summary of fieldwork carried out at each site is given in Appendix A, Table A.2.

Paired fields were located on the same farm in order to control for landscape and site-specific effects. They were matched as closely as possible in terms of soil type, slope, aspect and previous management. The only exception was at the Suffolk site (WAF) in 2011 where a suitable MC field was not available on site, so a paired field was chosen on a farm $8 \mathrm{~km}$ away. This pair was only used for some of the analyses (details below). Agricultural crop type and management were as similar as possible within each pair. Such field-scale comparisons have been shown to be a reliable way of determining effects of agri-environment management options (Kleijn and van Langevelde, 2006). All sites were managed organically (no conventionally-managed sites were available). Organic farming can support higher pollinator abundance and diversity, especially at the field scale (Gabriel et al., 2013; Lichtenberg et al., 2017), although with mixed results in grassland (Scheper et al., 2013). The implication for this study is that the observed abundance and/or diversity of pollinators is likely to be higher than had non-organic fields been used, at least in arable fields. However, as both treatments were organic, the comparison remains valid and any treatment effect should also apply to conventional systems; and perhaps to an even greater degree, as larger effect sizes have been observed with increased local contrast in floral resources (Scheper et al., 2015). 
In the event of unplanned differences in the cutting regime across paired fields at pasture sites, pollinator data from the affected sampling occasion(s) were excluded from analyses (Tables A.3 and A.4), because differences in cutting regime and sward structure have been shown to have a major short-term effect on pollinator abundance and diversity (Buri et al., 2014; Potts et al., 2009). All data from the Suffolk site (WAF) in 2011 were excluded from bumblebee and hoverfly analyses (although retained in solitary bee analyses) because the sown ley mixtures in the paired fields differed greatly in clover abundance (it was greater in the MC treatment; further details and justifications in Appendix A). The potential impacts of these decisions were assessed in separate analyses, which gave consistent results (Appendix B, Tables B.4-B.6 \& B.10) although with slightly weaker data-based model selection, indicating the decisions were justified.

\subsection{Estimating pollination service}

We monitored bumblebees, solitary bees and hoverflies as these are known to be the main insect pollinating taxa in the UK; butterflies contribute relatively little to crop pollination in northern Europe (Jennersten, 1984). Abundance (Section 2.2.1) and species richness (Section 2.2.2) of pollinators were used as proxies for pollination service (see Introduction for literature supporting the assumptions made here) as both have been directly linked to plant reproductive success and pollination service provision (Dainese et al., 2019; Winfree et al., 2018, 2015). Pollinator abundance was estimated using timed transect walks and species richness using pan traps ( $O^{\prime}$ Connor et al., 2019). Pollination service was also measured directly using phytometer plants (Section 2.2.3).

\subsubsection{Abundance}

Abundance within each taxon was measured as total numbers of individuals per field recorded during a field season. Standardised transect walks were used to assess numbers of individuals. Transect walks give a good indication of habitat associations as they are area-based rather than activity-based. At each site a $200 \mathrm{~m}$-long transect was set up in each treatment in the spring of 
front of the observer were recorded. Because many pollinator species are hard to identify outside a laboratory setting, unidentifiable pollinator specimens were netted and killed quickly with ethyl acetate for laboratory identification. Transects were set up at least $25 \mathrm{~m}$ from the end of the AF alley, or from the field boundary in the MC, to avoid edge effects. In AF systems, half of each transect $(100 \mathrm{~m})$ was situated in the centre of the alley and the other half ran along the edge of the alley in order to sample both environments. Transects were walked at a rate of $5 \mathrm{~m} \mathrm{~min}^{-1}$ between 10:45h and 15:45h, and only when weather conformed to UK Butterfly Monitoring Scheme standards (http://www.ukbms.org/Methods.aspx) as insect pollinators forage in these conditions. Weather conditions were monitored throughout the transect using a Kestrel 3500 hand-held weather meter. Transects were carried out from the end of March until the end of September in 2011 and from April-September in 2012 to encompass peak flower blooming and pollinator flight periods. At one site (WAF, site details in Appendix A) an additional survey round was undertaken in March 2013 to capture the flowering period of the tree species at that site.

One transect was walked in each treatment (AF or $\mathrm{MC}$ ) per visit. Sites were visited between four and six times during the season (number of successful visits depended on the weather and the farm management). At most sites, five visits were achieved in 2011 and four in 2012. Visits were at least a month apart to avoid re-sampling the same individuals on each visit. Although different sites were not sampled with equal intensity, each pair of fields within a site was sampled equally. Site was included in models as a random effect, allowing direct comparisons of abundance to be made.

\subsubsection{Species richness} Species richness was chosen as a suitable diversity measure because (a) it is often used in studies looking at the effects of agri-environmental management or habitat quality on pollinators (e.g. Kleijn and van Langevelde 2006, Concepción et al. 2012); (b) it is suitable for all spatial scales; and (c) it is an easily-understood index of community structure (Gotelli and Colwell, 2011). EstimateS was used for species richness calculations (Colwell, 2013). Sites were not all sampled an equal number of times, so rarefaction (bumblebees) and extrapolation (solitary bees) were used in order 
to allow analysis of species richness across all sites (Gotelli and Colwell, 2001; Colwell et al., 2012). Bumblebee data was rarefied to the lowest number of sampling occasions at any site $(n=4)$ as numbers caught were not high enough to allow reliable extrapolation. Solitary bee numbers were higher so species richness could reliably be extrapolated to the highest number of sampling occasions at any site $(n=14)$ (an analysis of rarefied solitary bee data gave consistent results, Table bumblebees) are difficult to tell apart so these two species were recorded as one aggregate species. All solitary bees were identified to species by Ellen Moss (University of Reading). Hoverfly species richness was not investigated.

Pan traps have been shown to be the best single method for assessing bee SR (Westphal et al., 2008; Nielsen et al., 2011). UV-bright pan traps were set up on each visit and left out from 08:00h17:00h. Three colours (one yellow, one blue and one white pan) were used at each sampling location as different pollinator groups may be attracted to different colours (Campbell and Hanula, 2007). Sampling locations were positioned in a diagonal line across an AF alley. Six sampling locations were used per treatment in 2011, and twelve sampling locations were used per treatment in 2012 (six sampling locations in each of 2 alleys). This pattern and orientation were mimicked in the MC control fields. Pan trap sampling was carried out on the same sampling occasions as transect walks.

At arable sites pan traps were positioned on stands at crop height. At pasture sites pans were placed on the ground on a square of black mulch fabric to ensure the same background colour at each position. Insects collected from each pan were bagged and taken back to the laboratory where they were frozen until identification.

\subsubsection{Seed production} In 2012 and 2013, phytometers (potted plants) were used to estimate pollination service directly at a subset of sites (Table A.2) as they are a reliable method for measuring pollination service 
(Woodcock et al., 2014). The plants chosen were California poppy (Eschscholtzia californica) as they are self-incompatible, pollinated by generalist species, do not occur in the landscape (therefore all pollen comes from the phytometers), and the seeds are easy to count. The phytometers used in this study performed well in field trials and plants from the same batch were used successfully in other studies (Hardman et al., 2016). Hardman et. al. (2016) give further justifications for choosing California poppy. Prior to exposure, five developing buds were tagged and all other buds removed. Plants were then placed in the field: on the ground in pasture systems and on upturned buckets in arable systems to ensure the flowers were level with the top of the crop. Phytometers were protected with chicken wire cages and 10 organic slug pellets per pot. They were watered as necessary.

Phytometers were exposed for two weeks in July and August, and additional flowers were tagged as they opened (up to 20 additional flowers in 2012, and 30 in 2013). Phytometers were then placed in pollinator exclusion cages while tagged fruits ripened (any subsequent developing buds were removed daily, and plants were watered as necessary). Seed set was assessed by counting the number of fully-developed seeds per fruit.

Phytometer positioning in the field followed the same pattern as the pan trap positions, but phytometer plants were positioned $5 \mathrm{~m}$ further down the alley so that they were not in the same place as the pan traps. In 2012, two arable and one pasture site were used and one phytometer plant was placed at each position. In 2013 the phytometer experiment was beset with issues. First, land use could not be kept the same as in 2012 because one of the arable sites changed the crop from arable to ley and although another arable site was set up with phytometers in 2013 , work there had to be abandoned due to a severe weed problem. Thus, in 2013 three pasture sites were used. Furthermore, in 2013 two plants were used per position at two of the three pasture sites but, due to unforeseen circumstances, only one plant was used per position at the third pasture site and at the (subsequently abandoned) arable site. Finally, due to an error, phytometer plants at two of 
the three sites (SD \& WAF) in 2013 were closer to each other in MC treatments than in AF treatments. In the third site (LHF) distances were equal. The implications of these issues are discussed later. For transparency, we include an analysis of the 2013 phytometer data and attempt to account for these discrepancies; however, the results merely serve to highlight the problems inherent in the dataset. Partly because of these discrepancies, phytometer data were analysed separately for 2012 and 2013.

\subsection{Estimation of other variables expected to influence abundance or species richness} Because it was not possible to control for effects other than treatment, several other possible predictors of pollinator and plant species richness and abundance were measured, based on the literature (Table A.5). These were: the species richness of insect-pollinated plants in field boundaries (both hedges and margins, method in Appendix A); the area covered by the field boundaries (measured from farm maps and Google Earth); the distance to the nearest field boundary from the data collection area (measured on the ground); the number of hedged field boundaries; the type of land use (arable or pasture); the percentage of the transect that was sunny (time estimated during transect); and the percentage of semi-natural habitat (SNH) in the surrounding landscape. \%SNH in a $1 \mathrm{~km}$ buffer around field perimeters was calculated from Priority Habitat Inventory for South East England using ArcMap 10 GIS software. This buffer size encompasses the predominant flight ranges of wild bees (Greenleaf et al., 2007; Zurbuchen et al., 2010). Further methodological details given in Appendix A.

Finally, because the effect of treatment on pollinator species richness and abundance may be mediated through treatment effects on plant species richness (Borer et al., 2012; Scherber et al., 2010), we estimated the plant species richness of the cropped area (method in Appendix A) and tested for correlations with pollinator abundance or species richness. In AF systems, the cropped area included the tree rows. 
An information theoretic (IT) approach was adopted, using model averaging to allow inferences to be drawn from weighted support over several models (multi-model inference). Standard IT practice is to first generate a highly-parameterised global model with all the biologically relevant parameters (Burnham and Anderson, 2002; Grueber et al., 2011; Harrison et al., 2018). The global model (which is not used for inference) is used to generate all possible lower-dimensional submodels (in effect, all possible hypotheses). These more parsimonious lower-dimensional models are then compared against each other to find out their relative worth. The ones with the highest relative worth are used for inference. Statistical analyses were carried out in R ( $R$ Development Core Team, 2019).

An extensive literature search was carried out to identify possible predictor variables for inclusion in global models (Table A.5) (Burnham et al., 2011; Elliott and Brook, 2007). The final choice of predictor variables and interactions included in global models was based on evidence from the literature and on basic data exploration. Variables that did not appear to be having a strong effect when investigated graphically were nonetheless included in global models if there was a scientific reason to suspect they might have some effect.

Global models (Table A.6) were all initially built as generalised linear mixed effects models (GLMMs), fitted by maximum likelihood. Model fit was based on the global model only (Burnham et al., 2011; Harrison et al., 2018; Symonds and Moussalli, 2011). To allow comparison of the relative strength of parameter estimates after model averaging, continuous independent variables were standardised prior to model building using the arm package (Gelman et al., 2013) or, for negative binomial models, the rescale function in R. For species richness and phytometer 2012 data, error structures were Poisson or Gaussian (gImer and Imer functions respectively, package Ime4 (Bates et al., 2015)). To reduce overdispersion, error structures for abundance models were Poissonlognormal, in which observation-level random effects are used, or negative binomial (glmer.nb function in package Ime4). Nested random effects were included in global models where possible 
because of the hierarchical nature of the study design. Where random effects explained none of the variance, they were removed from models; this resulted in single random effects (rather than nested) in some models (Table A.6). Model assumptions were verified by using standard model check plots to assess the residuals for temporal and spatial dependency. Where necessary, square root or log transformations of the response variable were used in linear mixed models (LMMs) fitted by maximum likelihood. Model validation of all global models indicated no problems (except in the phytometer 2013 global model which was not used, as explained below).

Global models were then used to generate all possible lower-dimensional models using the MuMIn package (Bartoń, 2019). A subset of plausible 'top' models that explained the data best was chosen from these candidate models using cut-off criteria for difference in $\mathrm{AlC}_{c}\left(\Delta_{i}\right)$ of 4 or less, always ensuring that $S$ (the number of models in the top models set) was less than the number of sites

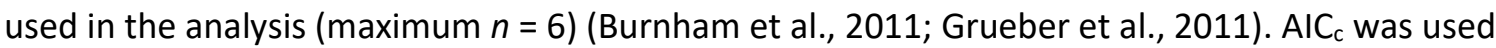
due to the small sample size. The 'top models' subset was then used for multi-model inference. This model-averaging approach allowed us to explicitly incorporate the model selection uncertainty that can result from small datasets, resulting in robust parameter estimates with reduced uncertainty and bias (Burnham and Anderson, 2002; Grueber et al., 2011). Model-averaged parameters were calculated using the natural average method (Burnham and Anderson, 2002).

It was necessary to use a negative binomial error structure for the hoverfly abundance dataset; these models were not accepted by the MuMIn package, so candidate model sets were generated by hand and then models were compared using package AICcmodavg (Mazerolle, 2019). Model averaged parameters were then calculated from the top model set by hand (Equations A.1 - A.3, Appendix A).

We would ideally have analysed the phytometer data from both years together, but the proposed global model suffered from multicollinearity. This was due to the 2013 dataset, so we analysed the 
model for 2013 phytometer data (P-2013, Table A.6) was unusable due to multicollinearity (Table B.12), and other variations of the model suffered from the same problem. These issues persisted when we attempted to analyse each site separately. We could not, therefore, reliably use a linear model for this analysis (Freckleton, 2011). Instead we carried out a Principal Components Analysis (PCA) using the prcomp function in R core package 'stats'. The variables included in the PCA were those originally identified as important when building the proposed global model. PCA is often used to reduce the potential number of model parameters by selecting informative variables (King and Jackson, 1999), but this was not possible here (see results).

When interpreting model-averaged results, the relative variable importance $\left(w_{i p}\right)$ indicates the strength of evidence for each variable. The larger the $w_{i p}$ is, the more important that variable is relative to the other predictor variables, and the more confidence we can have that it is a strong predictor of the observed response. Predictor variables are considered important if $w_{i p}>0.6$ and if the confidence intervals do not overlap with zero (Burnham and Anderson, 2002). Unless stated otherwise, model estimates are given at the mean of all other predictor variables.

\section{Results}

\subsection{Pollinator abundance}

\subsubsection{Bumblebee abundance} Pollinator abundance on transect walks was higher in AF than MC treatments (Figure 1a). A total of 1,979 bumblebees were recorded on transect walks. After eliminating sampling occasions where pasture sward structure or composition were incomparable (Appendix A), there were 1,159 bumblebees in total, of which 835 were recorded in the AF and 324 in the MC. The top models subset and results of model averaging show that the variables with the largest effect on bumblebee abundance are treatment, land use, and the interaction between these two (all have $\mathrm{w}_{i p}=1$ and $\mathrm{Cls}$ do not include zero, Tables 1 \& B.1). Of these three, the variable with the narrowest $\mathrm{Cl}$ is treatment. 
predictor of bumblebee abundance. Model estimated bumblebee abundance on any given transect was 1.8 in AF and 1.5 in MC. There is also very good evidence that the interaction between treatment and land use is important: model estimated bumblebee abundance was 7.6 times greater in silvoarable systems than in silvopasture systems (Figure 1a), and indeed model estimates of bumblebee abundance showed no difference between treatments in the pasture systems. In arable systems, model estimated bumblebee abundance was 2.4 times greater in AF than MC (abundance per transect $=7.0$ and 2.9 respectively). Bumblebee abundance was also affected by the amount of sunshine during transects and distance to the nearest boundary hedgerow, with fewer bumblebees observed further from boundary hedgerows (Table 1).

\subsubsection{Solitary bee abundance}

A total of 136 solitary bees were recorded on transects, of which 133 were seen in the AF treatments and 7 in MC. Solitary bee abundance was higher in AF treatments than MC treatments $\left(w_{i p}\right.$ treatment $=1, \mathrm{Cl}$ do not include zero, Figure $1 \mathrm{~b}$, Tables $1 \&$ B.2). Model estimated abundance of solitary bees on any given transect was 1.4 in $\mathrm{AF}$ and 0.7 in MC. In addition, solitary bee numbers were lower further from hedgerows and were affected by the amount of SNH in the landscape (Tables 1 \& B.2). As the amount of SNH in the surrounding landscape increased, numbers of solitary bees in $\mathrm{AF}$ treatments were unaffected but numbers in $\mathrm{MC}$ treatments increased: an increase in SNH from the mean of $11 \%$ to $35 \%$ resulted in more than a three-fold increase in numbers of solitary bees in MC systems (from an average of 0.7 to 2.3 individuals on any given transect).

\subsubsection{Hoverfly abundance}

A total of 1,793 hoverflies were recorded on transects (after elimination of all data collected in 2011 from site WAF, see Methods). Of these, 1,332 individuals were recorded in AF and 461 in MC. Hoverfly abundance was almost two times higher in $\mathrm{AF}$ than $\mathrm{MC}$ treatments ( $\mathrm{w}_{\text {ip }}$ treatment $=1, \mathrm{Cl}$ do not include zero, Tables $1 \&$ B.3, Figure $1 c \&$ d): model estimated abundance of hoverflies on any given transect was 5.5 in AF and 2.8 in MC. Land use was also an important predictor ( $w_{\text {ip }}$ land use $=1$, Cls do not include zero, Tables $1 \&$ B.3, Figure $1 \mathrm{c} \& \mathrm{~d}$ ): model estimated hoverfly 
abundance on any given transect was three times higher in arable than in pasture land ( 8.3 and 2.7 respectively). Treatment had a slightly narrower $\mathrm{Cl}$ than land use; there is therefore strong evidence that treatment was an important (or even the most important) predictor of hoverfly abundance. There is also weak evidence of an interaction between treatment and land use (Table 1): the AF treatment increased hoverfly abundance 2.9 -fold in arable systems but only 1.6 -fold in pasture systems. Although there is weak evidence of an interaction effect, we plot hoverfly abundance in arable and pasture land separately in Figure 1 because the far higher abundance in arable land made an interaction plot hard to read. There is weak evidence that larger boundary areas positively affected hoverfly abundance (Table 1 ). Date ${ }^{2}$ also affected hoverfly abundance: this is a known seasonal effect and the variable was included to improve model fit.

\subsection{Pollinator species richness (SR)} In total, 178 bumblebee individuals from 11 species were caught in pan traps (after excluding data from WAF 2011 and counting Bombus terrestris and B. lucorum as one aggregate species). All 11 species were found in AF treatments, and seven of these species were found in MC treatments. For solitary bees, a total of 1,249 individuals were caught. After eliminating from the dataset all unsuitable sampling occasions, then removing specimens in too poor a condition to identify $(n=6)$, there were 1,133 solitary bee individuals comprising 57 solitary bee species from 11 genera. 50 species were recorded in AF and 36 species in MC. There is no evidence of a treatment effect on either bumblebee or solitary bee SR: for both taxa, there is almost no difference between the bestranked model and the null model (Tables B.7 \& B.8), indicating that they are almost equally as likely as each other. Furthermore, treatment is not in any of the top bumblebee models (Tables 2 \& B.7). For both bumblebee and solitary bee SR, the predictor variables present in the top models subsets either have Cls which include zero or/and they have very low wip (Table 2). Solitary bee SR results were obtained by extrapolating solitary bee data to $n=14$ sampling occasions; rarefaction to $n=4$ gave very similar results (Appendix B, Table B.9 \& Figure B.1). 
For both bumblebee and solitary bee SR the low Akaike weights of all the top models (Tables B.7 \& B.8) indicate high model-selection uncertainty, reducing our confidence in the data-based choice of best models and reinforcing the need for multi-model inference (Burnham and Anderson, 2002). In future, more data may enable identification of a 'best' model and/or stronger inference. Although the data are not adequate to draw strong inference from the all-sites model, initial visualisation of solitary bee SR data (although not bumblebee data) suggested a difference between treatments at some sites. We therefore compared SR estimates at each site separately. This site-by-site analysis (Figure 2) showed that extrapolated SR was significantly higher in the AF treatment at sites CE in 2011, at WH in 2011 and 2012, and at WAF in 2012 and 2013 (on average it was 10.5 times higher in AF treatments). At WAF in 2011, LHF and SD the AF treatments had higher SR but not significantly so. At one site (RR) the MC treatment had higher SR, although not significantly so (Figure 2).

\subsection{Relationship between plant SR and higher trophic levels}

The effect of treatment on pollinator SR and abundance may be mediated through treatment effects on plant SR. To investigate this relationship, we tested Pearson's product moment correlation between plant SR and pollinator metrics. We found that plant SR and solitary bee SR were positively correlated $\left(r_{(8)}=0.67, p=0.04\right)$. No other pollinator metrics were correlated with plant SR.

\subsection{Seed production}

Seed set in 2012 was higher in the AF treatment than in the MC treatment ( $w_{i p}$ treatment $=1, \mathrm{Cls}$ do not include zero, Tables 3 \& B.11). From 36 plants (on each of which up to 20 buds were allowed to develop), 335 seeds were produced. Of these, 239 seeds came from the AF treatment and 96 from the MC. Model estimated seed set was 0.9 seeds per fruit in AF and 0.2 in MC. Distance to the nearest hedgerow affected seed set, with fewer seeds produced in phytometers further from 
hedgerows. In AF treatments, for example, model estimated seed set $100 \mathrm{~m}$ from the nearest hedge was 0.6 seeds per fruit whereas at $20 \mathrm{~m}$ it was 2.2 seeds per fruit.

414

415

In 2013 seed set was much higher per plant than in 2012: from 120 plants a total of 1,703 fruits were produced, containing 58,297 seeds. Of these, 23,006 seeds were produced in the AF treatment and 35,291 in MC. Mean number of seeds per fruit was 28 in AF and 39 in MC. We investigated the relative effect of variables in the dataset using the first two principal components from the PCA as they had eigenvalues greater than 1 and together explained $72.4 \%$ of the variance (Figure 3, Table B.13). The three most representative variables on PCs 1 and 2 were the distance between phytometers, followed by treatment and boundary area in joint second place (Figure B.3).

Figure 3 shows that different variables were important at different sites. At site WAF most of the variance was on PC1. Distance between phytometers was the variable most significantly associated ( $p<0.001$ ) with PC1. It had a correlation of 0.98 , was the largest contributor to this component $(43 \%)$ and had the highest quality of representation (cos2 =0.96) (Figure B.2, Table B.14). At WAF, the phytometers were 2.5 times further apart in the AF treatment than in the MC treatment, and the results indicate that this variable had a strong influence here. Treatment and hedge distance were also significantly associated with PC1 (both $p<0.001$ ) and were joint second in terms of both contribution (each $24 \%$ ) and quality (each $\cos 2=0.54$, Figure B.2, Table B.14): at WAF the hedges in the AF were over twice as far from the phytometers as they were in MC. Figure 3 indicates that the species richness of insect-pollinated plants in field boundaries was also a small contributor at WAF (Figures B.2 \& B.3), where it was higher in the MC treatment.

At the other two sites (LHF and SD), most of the variance was on PC2 (Figure 3). This component is dominated by boundary area: its contribution and quality of representation were almost three times greater than the next most important variable on PC2, which was treatment (Figures B.2 and B.3, Table B.14). Both LHF and SD had large differences in the boundary areas of the two 
treatments: at LHF the boundary area of the AF field was almost 3.5 times greater than in the MC; at $\mathrm{SD}$ the boundary area of the AF field was 12.5 times smaller than in the MC.

Although PCA can be used to reduce the potential number of model parameters, a regression analysis using the variables that contributed most to PCs 1 and 2 would be uninformative because they are all correlated with each other (Table B.12). The PCA results indicate that other variables were more important than treatment on both PCs, so we can draw no firm conclusions about the effect of treatment on seed set in the phytometer 2013 dataset.

\subsection{Summary of results}

Without exception, in all multi-model inference analyses where there was evidence that one or more variable(s) affected the response, treatment was the variable with the strongest evidence of an effect. Therefore, presented below (Table 4) is a summary of treatment effects. The size and direction of the effect is shown. Excluded from this summary are those analyses where there was no strength of evidence for any variable affecting pollinators or pollination. We also exclude the phytometer 2013 data.

Table 4 shows that overall, AF treatments had a positive effect on pollinators and pollination. We highlight below some of the nuances in these results:

(i) Solitary bee and hoverfly abundance were higher in AF treatments, regardless of land use, whereas bumblebee abundance was higher in AF treatments in arable systems only; in pasture systems bumblebees showed no evidence of a treatment effect.

(ii) For bumblebees and hoverflies, the positive response to AF treatments was greater in arable land than pastureland, although for hoverflies the evidence for this interaction was only weak.

(iii) SR differences were harder to detect than abundance differences, and differences were only observed at some sites. 
(iv) Only solitary bees showed a SR response to treatment; bumblebee SR showed no response. pollinator metrics.

\section{Discussion}

\subsection{Pollinator abundance}

The higher abundance of all three wild pollinator taxa (bumblebees, solitary bees and hoverflies) in AF compared to MC treatments is compelling evidence that modern AF systems in temperate climates can support higher numbers of pollinators and thus potentially greater pollination service than MC systems. This is supported by the 2012 phytometer results where we observed a pronounced treatment effect, with 4.5 times higher seed set in AF than MC. This confirms that the higher pollinator abundance in AF treatments in 2012 was being translated into increased pollination service in these systems.

Our findings are consistent with the literature, a large body of which shows that insect abundance displays strong local-scale responses to increased plant diversity (Lichtenberg et al., 2017). The observed increase in pollinator abundance is likely to be because the AF treatments, particularly the un-grazed ones, provided more floral, nesting and larval resources, more undisturbed areas, and a more diverse sward structure. For solitary bees in particular, local-scale habitat characteristics have been shown to have a strong influence on abundance (Hopfenmüller et al., 2014; Scheper et al., 2015) and this group showed a very strong positive response to both the AF treatment and proximity to hedgerows, which can be a good resource for wild bees (Garratt et al., 2017; Ponisio et al., 2019).

We also found landscape-scale effects on solitary bees: in MC treatments, a higher percentage of SNH in the surrounding landscape was related to higher solitary bee abundance, as observed elsewhere (Bukovinszky et al., 2017; Nicholson et al., 2017). The fact that this effect only occurred 
in MC treatments suggests that, for solitary bees, the influence of landscape-scale factors was outweighed by local-scale factors (i.e. the AF treatment), in agreement with other studies (Benjamin et al., 2014; Hopfenmüller et al., 2014). AF systems thus show great potential for supporting and conserving solitary bees in UK farmland as well as providing greater levels of pollination service.

Hoverfly abundance also exhibited a strong positive response to the AF treatment, in line with

findings that vegetation-structural traits and floral resource provision are important predictors of hoverfly abundance (Bartual et al., 2019; Haenke et al., 2009). Pollination service provision by hoverflies should therefore be higher in AF systems than in MC. Hoverfly abundance in both treatments was higher in arable than pasture land, which is likely to be because many hoverflies have aphidophagous larval stages so their abundance will be higher in land use types harbouring aphid populations (Haenke et al., 2009). These findings thus suggest the potential for greater natural pest control in AF systems, which has been observed in some AF systems elsewhere (Pumariño et al., 2015; Staton et al., 2019); further work would be necessary to confirm this.

Both bumblebees and hoverflies showed a greater response to treatment in arable than pasture land, in agreement with other studies which have observed greater effect sizes in arable (i.e. more simplified) landscapes (Carvell et al., 2011; Haenke et al., 2009; Scheper et al., 2015). In our study, the larger treatment effect in arable systems is likely to be due to the higher ecological contrast created at these sites (Marja et al., 2019): most of the pasture systems were grazed, thus removing understorey resources, whereas at arable sites the tree understoreys provided floral and nesting resources and overwintering habitat, which promote pollinating insect abundance (Häussler et al., 2017; Ramsden et al., 2015; Scheper et al., 2015). Incorporating fruit or nut trees into grazed silvopasture systems could better support insect pollinator populations through increased floral resources during the tree blossoming period (Häussler et al., 2017; Potts et al., 2009). Furthermore, our pasture sites were grazed by sheep which crop the vegetation closely and create a homogenous sward, reducing resources for pollinating insects. Other livestock, however, graze differently and so 
there may be potentially greater resources for pollinating insects in other livestock systems

512 (Vanbergen et al., 2014, 2006). These factors highlight the need for careful design of AF systems, ensuring that ecosystem service outcomes are explicitly planned right from the design stage rather than being considered a coincidental bonus. Payments for Ecosystem Services schemes could help focus attention on service provision at the planning stage, and this study provides the type of quantitative evidence - linking land management to ecosystem service provision - that is required when designing these schemes (DEFRA, 2014).

Pollinator activity was not recorded, so it is impossible to know whether the observed treatment effect was having a population-level effect or simply attracting pollinators from elsewhere. It is, however, possible that the increased pollinator abundance in AF systems may be at least partly due to population-level effects as AF systems can provide many of the nesting and larval development requirements of pollinators. Nevertheless, we can say with a high degree of confidence that the higher pollinator abundance observed in AF treatments means that AF systems are a useful resource for pollinators and can therefore support pollinator populations in the wider countryside.

\subsection{Pollinator species richness} In contrast to pollinator abundance, pollinator SR did not exhibit such a pronounced treatment effect (as also observed elsewhere, e.g. Bukovinszky et al. (2017)). Our confidence in the results of the all-sites analyses was low and the results indicated a need for more data: it is thus likely that we did not sample sufficiently to accurately estimate pollinator SR, which is known to be hard to thoroughly sample especially over a small number of years (Russo et al., 2015). Increased sampling effort would allow more robust analyses of treatment effects across sites in future.

532 Bumblebees and solitary bees differed in their response to treatment, as also found by others

533 (Kleijn and van Langevelde, 2006; Scheper et al., 2015): bumblebee SR showed no response to treatment, whereas solitary bee SR was higher in the AF treatment in some years at three of the six study sites. In agreement with other studies, we found different solitary bee SR responses in 
grassland compared to arable land. One of the pasture sites with increased SR in the AF treatment

537 (site $\mathrm{CE}$ ) also had the highest recorded amount of SNH in the surrounding landscape, concurring with findings that agri-environmental management (AEM) in grassland has the greatest effect on solitary bee SR in landscapes with more SNH (Concepción et al., 2012 - but see Kleijn and van Langevelde, 2006). Conversely, the arable site that showed a treatment effect (site WH) was in a highly homogenous, intensively-farmed region and had the least amount of SNH around it. This is in

542 line with studies showing that AEM in arable landscapes had the greatest effect on solitary bee SR when there was little SNH in the surrounding landscape and where the management created large local contrast in resources (Concepción et al., 2012; Holzschuh et al., 2007; Scheper et al., 2015).

The silvoarable system at WH provided great floral and structural diversity in the tree rows, thereby creating a large ecological contrast: this was likely to be the driver of the observed SR increase

547 here.

The third site to show increased solitary bee SR in the AF treatment was another pasture site (WAF), but this one was in a very intensively-farmed landscape with little SNH. It is possible that here, the increased solitary bee SR may have been partly due to the fact that the site was un-grazed and well-established (Table A.1), allowing the tree rows to develop a structurally complex understorey that persisted from one year to the next (Buri et al., (2014) found cumulative (over time) positive effects of uncut grass refugia on wild bee SR). Furthermore, it had the largest contrast in within-field plant SR of any site, with over three times greater plant SR in the AF treatment: we found that, across all sites, solitary bee SR was positively correlated with plant SR so this may also have contributed to the observed difference in solitary bee SR at WAF. This correlation between solitary bee and plant SR is in agreement with other findings (Isbell et al., 2017; Lichtenberg et al., 2017; Sutter et al., 2017) and suggests that the treatment effect on SR was due to the higher plant diversity in these systems. This once again highlights the importance of careful design of AF systems to achieve the greatest possible increase in ecosystem service provision and biodiversity conservation. 


\subsection{Pollination service}

The 2012 phytometer experiment showed higher seed set and thus greater pollination service in AF treatments, which is most likely to be due to the higher abundance of insect pollinators in AF treatments. Our findings are in line with previous studies linking insect pollinator abundance to pollination service (Winfree et al., 2015; Woodcock et al., 2019). The higher solitary bee SR in some of the AF treatments may also have contributed, as species richness has been shown to support pollination service (Albrecht et al., 2012; Dainese et al., 2019; Eeraerts et al., 2019) although its contribution to service delivery is inferior to that of abundance (Kleijn et al., 2015).

The phytometer results were inconsistent across the two years, although it is likely that the fieldwork issues in 2013 and experimental design were partly responsible, resulting in a very poor quality dataset. The large difference in seed set in the two years is likely to have been because in 2012 there was one plant per position whereas in 2013 there were two plants per position. As $E$. californica is self-incompatible, using a single plant per position is likely to have limited pollen availability in 2012. Also, in 2013 the distance between phytometers was smaller in MC treatments at two of the three sites (and equal in the third - hence its strong correlation with treatment in the proposed global model, Table B.12). As seed set has been shown to increase at higher flower densities (Dauber et al., 2010; Seifan et al., 2014) the distance between phytometers may have caused density-dependent effects on pollination, resulting in higher seed set where phytometers were closer together. Other variables likely to contribute indirectly to pollination (e.g. distance to the nearest hedgerow, field boundary area) were also correlated with treatment in the 2013 proposed global model (Table B.12) and were shown to be more important than, or as important as, treatment in the PCA. As a result, we cannot confidently ascribe the higher seed set in MC to any one variable and we suggest re-doing the phytometer experiment to confirm the presence and direction of any treatment effect. However, we remain confident in the conclusions drawn from the 2012 phytometer data. 


\section{Conclusions}

588

589

590

591

592

593

594

595

596

597

598

599

600

601

602

603

604

605

606

607

608

This work presents strong empirical evidence that UK AF systems can support greater numbers of wild insect pollinators, greater pollination service and, at some sites, greater wild bee species richness. This could benefit both wild plant populations and insect pollinated agricultural crops in areas near AF systems. In Europe there is growing interest in the implementation of modern AF systems and this study provides robust evidence of its benefits to pollinators. These findings, taken together with evidence that $\mathrm{AF}$ systems can also produce more biomass per unit area than $\mathrm{MC}$ systems (Isbell et al., 2017; Sereke et al., 2015), means that AF systems may have a part to play in the sustainable intensification of agriculture. Our study adds to the body of evidence supporting the uptake of AF in temperate intensive farming systems. Our work also highlights that the provision of additional ecosystem services - i.e. ecosystem services other than biomass production - should be considered at the design stage of new AF systems to ensure the greatest possible benefit is realised.

\section{Acknowledgements}

The authors thank the farmers who allowed their fields to be surveyed. This work was funded by the University of Reading Research Endowment Trust Fund and the Organic Research Centre. Additional support was provided through The Nineveh Charitable Trust, an intern (Sophie Anderson) funded through the BBSRC Doctoral Training Partnership's Research Experience Placement scheme, and two interns (Will Smith and Patrick Ingle-Finch) funded by Reading University's Undergraduate Research Opportunities Programme.

\section{Declaration of interest}

The authors declare they have no conflicts of interest. 


\section{References}

Albrecht, M., Schmid, B., Hautier, Y., Müller, C.B., Mu, C.B., 2012. Diverse pollinator communities enhance plant reproductive success. Proc. R. Soc. London. Ser. B Biol. Sci. 279, 4845-4852. doi:10.1098/rspb.2012.1621

Bartoń, K., 2019. Package “MuMIn”: Multi-model inference. R package version 1.43.15.

Bartual, A.M., Sutter, L., Bocci, G., Moonen, A.-C., Cresswell, J., Entling, M., Giffard, B., Jacot, K., Jeanneret, P., Holland, J., Pfister, S., Pintér, O., Veromann, E., Winkler, K., Albrecht, M., 2019. The potential of different semi-natural habitats to sustain pollinators and natural enemies in European agricultural landscapes. Agric. Ecosyst. Environ. 279, 43-52. doi:10.1016/J.AGEE.2019.04.009

Batáry, P., Dicks, L. V., Kleijn, D., Sutherland, W.J., 2015. The role of agri-environment schemes in conservation and environmental management. Conserv. Biol. 29, 1006-1016. doi:10.1111/cobi.12536

Bates, D., Maechler, M., Bolker, B., Walker, S., 2015. Fitting Linear Mixed-Effects Models Using Ime4. J. Stat. Softw. 67, 1-48.

Benjamin, F.E., Reilly, J.R., Winfree, R., 2014. Pollinator body size mediates the scale at which land use drives crop pollination services. J. Appl. Ecol. 51, 440-449. doi:10.1111/1365-2664.12198

Borer, E.T., Seabloom, E.W., Tilman, D., 2012. Plant diversity controls arthropod biomass and temporal stability. Ecol. Lett. 15, 1457-1464. doi:10.1111/ele.12006

Breeze, T.D., Bailey, A.P., Balcombe, K.G., Potts, S.G., 2011. Pollination services in the UK: How important are honeybees? Agric. Ecosyst. Environ. 142, 137-143. doi:10.1016/J.AGEE.2011.03.020

Briggs, H.M., Perfecto, I., Brosi, B.J., 2013. The Role of the Agricultural Matrix: Coffee Management and Euglossine Bee (Hymenoptera: Apidae: Euglossini) Communities in Southern Mexico. 
634

635

636

637

638

639

640

641

642

643

644

645

646

647

648

649

650

651

652

653

654

655

656

Bukovinszky, T., Verheijen, J., Zwerver, S., Klop, E., Biesmeijer, J.C., Wäckers, F.L., Prins, H.H.T., Kleijn, D., 2017. Exploring the relationships between landscape complexity, wild bee species richness and reproduction, and pollination services along a complexity gradient in the Netherlands. Biol. Conserv. 214, 312-319. doi:10.1016/J.BIOCON.2017.08.027

Buri, P., Humbert, J.-Y., Arlettaz, R., 2014. Promoting Pollinating Insects in Intensive Agricultural Matrices: Field-Scale Experimental Manipulation of Hay-Meadow Mowing Regimes and Its Effects on Bees. PLoS One 9, e85635. doi:10.1371/journal.pone.0085635

Burnham, K.P., Anderson, D.R., 2002. Model Selection and Multimodel Inference. A Practical Information-Theoretic Approach, Second. ed. Springer, New York.

Burnham, K.P., Anderson, D.R., Huyvaert, K.P., 2011. AIC model selection and multimodel inference in behavioral ecology: some background, observations, and comparisons. Behav. Ecol. Sociobiol. 65, 23-35. doi:10.1007/s00265-010-1029-6

Butler, S.J., Brooks, D., Feber, R.E., Storkey, J., Vickery, J.A., Norris, K., 2009. A cross-taxonomic index for quantifying the health of farmland biodiversity. J. Appl. Ecol. 46, 1154-1162. doi:10.1111/j.1365-2664.2009.01709.x

Campbell, J.W., Hanula, J.L., 2007. Efficiency of Malaise traps and colored pan traps for collecting flower visiting insects from three forested ecosystems. J. Insect Conserv. 11, 399-408. doi:10.1007/s10841-006-9055-4

Carvell, C., Osborne, J.L., Bourke, A.F.G., Freeman, S.N., Pywell, R.F., Heard, M.S., 2011. Bumble bee species' responses to a targeted conservation measure depend on landscape context and habitat quality. Ecol. Appl. 21, 1760-1771. doi:10.1890/10-0677.1

Castle, D., Grass, I., Westphal, C., 2019. Fruit quantity and quality of strawberries benefit from enhanced pollinator abundance at hedgerows in agricultural landscapes. Agric. Ecosyst. 
658

659

660

661

662

663

664

665

666

667

668

669

670

671

672

673

674

675

676

677

678

679

680

Colwell, R.K., 2013. EstimateS: Statistical estimation of species richness and shared species from samples. User's Guide and application published at: http://purl.oclc.org/estimates.

Concepción, E.D., Díaz, M., Kleijn, D., Báldi, A., Batáry, P., Clough, Y., Gabriel, D., Herzog, F., Holzschuh, A., Knop, E., Marshall, E.J.P., Tscharntke, T., Verhulst, J., 2012. Interactive effects of landscape context constrain the effectiveness of local agri-environmental management. J. Appl. Ecol. 49, 695-705. doi:10.1111/j.1365-2664.2012.02131.x

Dainese, M., Martin, E.A., Aizen, M., Albrecht, M., Bartomeus, I., Bommarco, R., Carvalheiro, L.G., Chaplin-Kramer, R., Gagic, V., Garibaldi, L.A., Ghazoul, J., Grab, H., Jonsson, M., Karp, D.S., Kennedy, C.M., Kleijn, D., Kremen, C., Landis, D.A., Letourneau, D.K., Marini, L., Poveda, K., Rader, R., Smith, H.G., Tscharntke, T., Andersson, G.K.S., Badenhausser, I., Baensch, S., Bezerra, A.D.M., Bianchi, F.J.J.A., Boreux, V., Bretagnolle, V., Caballero-Lopez, B., Cavigliasso, P., Cetkovic, A., Chacoff, N.P., Classen, A., Cusser, S., Silva, F.D. da S. e, Groot, G.A. de, Dudenhoffer, J.H., Ekroos, J., Fijen, T., Franck, P., Freitas, B.M., Garratt, M.P.D., Gratton, C., Hipolito, J., Holzschuh, A., Hunt, L., Iverson, A.L., Jha, S., Keasar, T., Kim, T.N., Kishinevsky, M., Klatt, B.K., Klein, A., Krewenka, K.M., Krishnan, S., Larsen, A.E., Lavigne, C., Leire, H., Maas, B., Nesper, M., Mallinger, R.E., Martinez, E., Martinez-Salinas, A., Meehan, T.D., Mitchell, M.G.E., Molina, G.A.R., Nilsson, L., O’Rourke, M., Peters, M.K., Plecas, M., Potts, Si.G., Ramos, D. de L., Rosenheim, J.A., Rundlof, M., Rusch, A., Saez, A., Scheper, J., Schleuning, M., Schmack, J., Sciligo, A.R., Seymour, C., Stanley, D.A., Stewart, R., Stout, J.C., Sutter, L., Takada, M.B., Taki, H., Tamburini, G., Tschumi, M., Viana, B.F., Westphal, C., Wilcox, B.K., Wratten, S.D., Yoshioka, A., Zaragoza, C., Zhang, W., Zou, Y., Steffan-Dewenter, I., 2019. A global synthesis reveals biodiversity-mediated benefits for crop production. Sci. Adv. 5, eaax0121. doi:10.1126/sciadv.aax0121 
682

683

684

685

686

687

688

689

690

691

692

693

694

695

696

697

698

699

700

701

702

703

704

705

706

Roberts, S.P.M., Sõber, V., Settele, J., Steffan-Dewenter, I., Stout, J.C., Teder, T., Tscheulin, T., Vivarelli, D., Petanidou, T., 2010. Effects of patch size and density on flower visitation and seed set of wild plants: A pan-European approach. J. Ecol. 98, 188-196. doi:10.1111/j.13652745.2009.01590.x

DEFRA, 2014. Defra Payments for Ecosystem Services ( PES ) Pilot Projects : Review of key findings 2011-2013.

Deguines, N., Jono, C., Baude, M., Henry, M., Julliard, R., Fontaine, C., 2014. Large-scale trade-off between agricultural intensification and crop pollination services. Front. Ecol. Environ. 12, 212-217. doi:10.1890/130054

Dicks, L. V., Bardgett, R.D., Bell, J., Benton, T.G., Booth, A., Bouwman, J., Brown, C., Bruce, A., Burgess, P.J., Butler, S.J., Crute, I., Dixon, F., Drummond, C., Freckleton, R.P., Gill, M., Graham, A., Hails, R.S., Hallett, J., Hart, B., Hillier, J.G., Holland, J.M., Huxley, J.N., Ingram, J.S.I., King, V., MacMillan, T., McGonigle, D.F., McQuaid, C., Nevard, T., Norman, S., Norris, K., Pazderka, C., Poonaji, I., Quinn, C.H., Ramsden, S.J., Sinclair, D., Siriwardena, G.M., Vickery, J.A., Whitmore, A.P., Wolmer, W., Sutherland, W.J., 2013. What do we need to know to enhance the environmental sustainability of agricultural production? A prioritisation of knowledge needs for the UK food system. Sustain. 5, 3095-3115. doi:10.3390/su5073095

Eeraerts, M., Smagghe, G., Meeus, I., 2019. Pollinator diversity, floral resources and semi-natural habitat, instead of honey bees and intensive agriculture, enhance pollination service to sweet cherry. Agric. Ecosyst. Environ. 284. doi:10.1016/j.agee.2019.106586

Elliott, L.P., Brook, B.W., 2007. Revisiting Chamberlin: Multiple Working Hypotheses for the 21st Century. Bioscience 57, 608-614. doi:10.1641/b570708

Fijen, T.P.M., Scheper, J.A., Boom, T.M., Janssen, N., Raemakers, I., Kleijn, D., 2018. Insect pollination is at least as important for marketable crop yield as plant quality in a seed crop. Ecol. Lett. 21, 1704-1713. doi:10.1111/ele.13150 
Foley, J.A., Defries, R., Asner, G.P., Barford, C., Bonan, G., Carpenter, S.R., Chapin, F.S., Coe, M.T., Daily, G.C., Gibbs, H.K., Helkowski, J.H., Holloway, T., Howard, E.A., Kucharik, C.J., Monfreda, C., Patz, J.A., Prentice, I.C., Ramankutty, N., Snyder, P.K., 2005. Global Consequences of Land Use. Science (80-. ). 309, 570-574. doi:10.1126/science.1111772

Freckleton, R.P., 2011. Dealing with collinearity in behavioural and ecological data: Model averaging and the problems of measurement error. Behav. Ecol. Sociobiol. 65, 91-101. doi:10.1007/s00265-010-1045-6

Gabriel, D., Sait, S.M., Kunin, W.E., Benton, T.G., 2013. Food production vs. biodiversity: comparing organic and conventional agriculture. J. Appl. Ecol. 50, 355-364. doi:10.1111/13652664.12035

Garibaldi, L.A., Aizen, M.A., Klein, A.M., Cunningham, S.A., Harder, L.D., 2011a. Global growth and stability of agricultural yield decrease with pollinator dependence. Proc. Natl. Acad. Sci. U. S. A. $108,5909-14$. doi:10.1073/pnas.1012431108

Garibaldi, L.A., Gemmill-Herren, B., D’Annolfo, R., Graeub, B.E., Cunningham, S.A., Breeze, T.D., 2016. Farming Approaches for Greater Biodiversity, Livelihoods, and Food Security. Trends Ecol. Evol. 32, 68-80. doi:10.1016/j.tree.2016.10.001

Garibaldi, L.A., Steffan-Dewenter, I., Winfree, R., Aizen, M.A., Bommarco, R., Cunningham, S.A., Kremen, C., Carvalheiro, L.G., Harder, L.D., Afik, O., Bartomeus, I., Benjamin, F., Boreux, V., Cariveau, D., Chacoff, N.P., Dudenhoffer, J.H., Freitas, B.M., Ghazoul, J., Greenleaf, S., Hipolito, J., Holzschuh, A., Howlett, B., Isaacs, R., Javorek, S.K., Kennedy, C.M., Krewenka, K.M., Krishnan, S., Mandelik, Y., Mayfield, M.M., Motzke, I., Munyuli, T., Nault, B.A., Otieno, M., Petersen, J., Pisanty, G., Potts, S.G., Rader, R., Ricketts, T.H., Rundlof, M., Seymour, C.L., Schuepp, C., Szentgyorgyi, H., Taki, H., Tscharntke, T., Vergara, C.H., Viana, B.F., Wanger, T.C., Westphal, C., Williams, N., Klein, A.M., 2013. Wild Pollinators Enhance Fruit Set of Crops Regardless of Honey Bee Abundance. Science (80-. ). 339, 1608-1611. 
733

734

735

736

737

738

Garibaldi, L.A., Steffan-Dewenter, I., Kremen, C., Morales, J.M., Bommarco, R., Cunningham, S.A., Carvalheiro, L.G., Chacoff, N.P., Dudenhöffer, J.H., Greenleaf, S.S., Holzschuh, A., Isaacs, R., Krewenka, K., Mandelik, Y., Mayfield, M.M., Morandin, L.A., Potts, S.G., Ricketts, T.H., Szentgyörgyi, H., Viana, B.F., Westphal, C., Winfree, R., Klein, A.M., 2011b. Stability of pollination services decreases with isolation from natural areas despite honey bee visits. Ecol. Lett. 14, 1062-1072. doi:10.1111/J.1461-0248.2011.01669.X@10.1111/(ISSN)14610248.ANTHROPOGENIC-CHANGE

Garratt, M.P.D., Breeze, T.D., Jenner, N., Polce, C., Biesmeijer, J.C., Potts, S.G., 2014. Avoiding a bad apple: Insect pollination enhances fruit quality and economic value. Agric. Ecosyst. Environ. 184, 34-40. doi:10.1016/J.AGEE.2013.10.032

Garratt, M.P.D., Senapathi, D., Coston, D.J., Mortimer, S.R., Potts, S.G., 2017. The benefits of hedgerows for pollinators and natural enemies depends on hedge quality and landscape context. Agric. Ecosyst. Environ. 247, 363-370. doi:10.1016/j.agee.2017.06.048

Gelman, A., Su, Y.-S., Yajima, M., Hill, J., Pittau, M.G., Kerman, J., Zheng, T., Dorie, V., 2013. Package "arm". Data Analysis Using Regression and Multilevel/Hierarchical Models.

Goulson, D., Nicholls, E., Botías, C., Rotheray, E.L., 2015. Bee declines driven by combined stress from parasites, pesticides, and lack of flowers. Science 347, 1255957. doi:10.1126/science.1255957

Grab, H., Branstetter, M.G., Amon, N., Urban-Mead, K.R., Park, M.G., Gibbs, J., Blitzer, E.J., Poveda, K., Loeb, G., Danforth, B.N., 2019. Agriculturally dominated landscapes reduce bee phylogenetic diversity and pollination services. Science (80-. ). 363, 282-284. doi:10.1126/SCIENCE.AAT6016 
757

758

759

760

761

762

763

764

765

766

767

768

769

770

771

772

Grueber, C.E., Nakagawa, S., Laws, R.J., Jamieson, I.G., 2011. Multimodel inference in ecology and evolution: challenges and solutions. J. Evol. Biol. 24, 699-711. doi:10.1111/j.1420$9101.2010 .02210 . x$

Haenke, S., Scheid, B., Schaefer, M., Tscharntke, T., Thies, C., 2009. Increasing syrphid fly diversity and density in sown flower strips within simple vs. complex landscapes. J. Appl. Ecol. 46, 1106-1114. doi:10.1111/j.1365-2664.2009.01685.x

Hardman, C.J., Norris, K., Nevard, T.D., Hughes, B., Potts, S.G., 2016. Delivery of floral resources and pollination services on farmland under three different wildlife-friendly schemes. Agric. Ecosyst. Environ. 220, 142-151. doi:10.1016/j.agee.2016.01.015

Harrison, X.A., Donaldson, L., Correa-Cano, M.E., Evans, J., Fisher, D.N., Goodwin, C.E.D., Robinson, B.S., Hodgson, D.J., Inger, R., 2018. A brief introduction to mixed effects modelling and multimodel inference in ecology. PeerJ 2018. doi:10.7717/peerj.4794

Hass, A.L., Liese, B., Heong, K.L., Settele, J., Tscharntke, T., Westphal, C., 2018. Plant-pollinator interactions and bee functional diversity are driven by agroforests in rice-dominated landscapes. Agric. Ecosyst. Environ. 253, 140-147. doi:10.1016/J.AGEE.2017.10.019

Häussler, J., Sahlin, U., Baey, C., Smith, H.G., Clough, Y., 2017. Pollinator population size and pollination ecosystem service responses to enhancing floral and nesting resources. Ecol. Evol. doi:10.1002/ece3.2765

Hoehn, P., Steffan-Dewenter, I., Tscharntke, T., 2012. Relative contribution of agroforestry, rainforest and openland to local and regional bee diversity. Biodivers. Conserv. 19, 21892200. doi:10.1007/s10531-010-9831-z

Hoehn, P., Tscharntke, T., Tylianakis, J.M., Steffan-Dewenter, I., 2008. Functional group diversity of bee pollinators increases crop yield. Proc. R. Soc. B Biol. Sci. 275, 2283-2291. 
781

782

783

784

Holzschuh, A., Steffan-Dewenter, I., Kleijn, D., Tscharntke, T., 2007. Diversity of flower-visiting bees in cereal fields: effects of farming system, landscape composition and regional context. J. Appl. Ecol. 44, 41-49. doi:10.1111/j.1365-2664.2006.01259.x

Hopfenmüller, S., Steffan-Dewenter, I., Holzschuh, A., 2014. Trait-specific responses of wild bee communities to landscape composition, configuration and local factors. PLoS One 9. doi:10.1371/journal.pone.0104439

IPBES, 2019. Global Assessment Report on Biodiversity and Ecosystem Services | IPBES. IPBES secretariat, Bonn, Germany.

Isbell, F., Adler, P.R., Eisenhauer, N., Fornara, D., Kimmel, K., Kremen, C., Letourneau, D.K., Liebman, M., Polley, H.W., Quijas, S., Scherer-Lorenzen, M., 2017. Benefits of increasing plant diversity in sustainable agroecosystems. J. Ecol. 105, 871-879. doi:10.1111/1365-2745.12789

Jennersten, O., 1984. Flower visitation and pollination efficiency of some North European butterflies. Oecologia 63, 80-89. doi:10.1007/BF00379789

Jose, S., 2009. Agroforestry for ecosystem services and environmental benefits: an overview. Agrofor. Syst. 76, 1-10. doi:10.1007/s10457-009-9229-7

Kallioniemi, E., Åström, J., Rusch, G.M., Dahle, S., Åström, S., Gjershaug, J.O., 2017. Local resources, linear elements and mass-flowering crops determine bumblebee occurrences in moderately intensified farmlands. Agric. Ecosyst. Environ. 239, 90-100. doi:10.1016/J.AGEE.2016.12.039

Kay, S., Crous-Duran, J., Ferreiro-Domínguez, N., García de Jalón, S., Graves, A., Moreno, G., Mosquera-Losada, M.R., Palma, J.H.N., Roces-Díaz, J. V., Santiago-Freijanes, J.J., Szerencsits, E., Weibel, R., Herzog, F., 2018. Spatial similarities between European agroforestry systems and ecosystem services at the landscape scale. Agrofor. Syst. 92, 1075-1089. doi:10.1007/s10457-017-0132-3 
Kay, S., Kühn, E., Albrecht, M., Sutter, L., Szerencsits, E., Herzog, F., 2019. Agroforestry can enhance foraging and nesting resources for pollinators with focus on solitary bees at the landscape scale. Agrofor. Syst. 1-9. doi:10.1007/s10457-019-00400-9

King, J.R., Jackson, D.A., 1999. Variable selection in large environmental data sets using principal components analysis. Environmetrics 10, 67-77. doi:10.1002/(SICI)1099095X(199901/02)10:1<67::AID-ENV336>3.0.CO;2-0

Klatt, B.K., Holzschuh, A., Westphal, C., Clough, Y., Smit, I., Pawelzik, E., Tscharntke, T., 2013. Bee pollination improves crop quality, shelf life and commercial value. Proc. R. Soc. B Biol. Sci. 281. doi:10.1098/rspb.2013.2440

Kleijn, D., van Langevelde, F., 2006. Interacting effects of landscape context and habitat quality on flower visiting insects in agricultural landscapes. Basic Appl. Ecol. 7, 201-214. doi:http://dx.doi.org/10.1016/j.baae.2005.07.011

Kleijn, D., Winfree, R., Bartomeus, I., Carvalheiro, L.G., Henry, M., Isaacs, R., Klein, A.-M., Kremen, C., M'Gonigle, L.K., Rader, R., Ricketts, T.H., Williams, N.M., Lee Adamson, N., Ascher, J.S., Báldi, A., Batáry, P., Benjamin, F., Biesmeijer, J.C., Blitzer, E.J., Bommarco, R., Brand, M.R., Bretagnolle, V., Button, L., Cariveau, D.P., Chifflet, R., Colville, J.F., Danforth, B.N., Elle, E., Garratt, M.P.D., Herzog, F., Holzschuh, A., Howlett, B.G., Jauker, F., Jha, S., Knop, E., Krewenka, K.M., Le Féon, V., Mandelik, Y., May, E.A., Park, M.G., Pisanty, G., Reemer, M., Riedinger, V., Rollin, O., Rundlöf, M., Sardiñas, H.S., Scheper, J., Sciligo, A.R., Smith, H.G., Steffan-Dewenter, I., Thorp, R., Tscharntke, T., Verhulst, J., Viana, B.F., Vaissière, B.E., Veldtman, R., Westphal, C., Potts, S.G., 2015. Delivery of crop pollination services is an insufficient argument for wild pollinator conservation. Nat. Commun. 6. doi:10.1038/ncomms8414

Klein, A.-M., Vaissière, B.E., Cane, J.H., Steffan-Dewenter, I., Cunningham, S.A., Kremen, C., Tscharntke, T., 2007. Importance of pollinators in changing landscapes for world crops. Proc. R. Soc. B Biol. Sci. 274, 303-313. doi:10.1098/rspb.2006.3721 
Kovács-Hostyánszki, A., Espíndola, A., Vanbergen, A.J., Settele, J., Kremen, C., Dicks, L. V., 2017. Ecological intensification to mitigate impacts of conventional intensive land use on pollinators and pollination. Ecol. Lett. doi:10.1111/ele.12762

Kuyah, S., Öborn, I., Jonsson, M., 2017. Regulating Ecosystem Services Delivered in Agroforestry Systems, in: Dagar, J.C., Tewari, V.P. (Eds.), Agroforestry: Anecdotal to Modern Science. Springer Singapore, Singapore, pp. 797-815. doi:10.1007/978-981-10-7650-3_33

Lichtenberg, E.M., Kennedy, C.M., Kremen, C., Batáry, P., Berendse, F., Bommarco, R., BosquePérez, N.A., Carvalheiro, L.G., Snyder, W.E., Williams, N.M., Winfree, R., Klatt, B.K., Åström, S., Benjamin, F., Brittain, C., Chaplin-Kramer, R., Clough, Y., Danforth, B., Diekötter, T., Eigenbrode, S.D., Ekroos, J., Elle, E., Freitas, B.M., Fukuda, Y., Gaines-Day, H.R., Grab, H., Gratton, C., Holzschuh, A., Isaacs, R., Isaia, M., Jha, S., Jonason, D., Jones, V.P., Klein, A.-M., Krauss, J., Letourneau, D.K., Macfadyen, S., Mallinger, R.E., Martin, E.A., Martinez, E., Memmott, J., Morandin, L., Neame, L., Otieno, M., Park, M.G., Pfiffner, L., Pocock, M.J.O., Ponce, C., Potts, S.G., Poveda, K., Ramos, M., Rosenheim, J.A., Rundlöf, M., Sardiñas, H., Saunders, M.E., Schon, N.L., Sciligo, A.R., Sidhu, C.S., Steffan-Dewenter, I., Tscharntke, T., Veselý, M., Weisser, W.W., Wilson, J.K., Crowder, D.W., 2017. A global synthesis of the effects of diversified farming systems on arthropod diversity within fields and across agricultural landscapes. Glob. Chang. Biol. doi:10.1111/gcb.13714

Lin, M., Huybers, P., 2012. Reckoning wheat yield trends. Environ. Res. Lett. 7, 024016. doi:10.1088/1748-9326/7/2/024016

Marja, R., Kleijn, D., Tscharntke, T., Klein, A., Frank, T., Batáry, P., 2019. Effectiveness of agrienvironmental management on pollinators is moderated more by ecological contrast than by landscape structure or land-use intensity. Ecol. Lett. ele.13339. doi:10.1111/ele.13339

Martin, E.A., Dainese, M., Clough, Y., Báldi, A., Bommarco, R., Gagic, V., Garratt, M.P.D., Holzschuh, A., Kleijn, D., Kovács-Hostyánszki, A., Marini, L., Potts, S.G., Smith, H.G., Al Hassan, D., 
Albrecht, M., Andersson, G.K.S., Asís, J.D., Aviron, S., Balzan, M. V., Baños-Picón, L., Bartomeus, I., Batáry, P., Burel, F., Caballero-López, B., Concepción, E.D., Coudrain, V., Dänhardt, J., Diaz, M., Diekötter, T., Dormann, C.F., Duflot, R., Entling, M.H., Farwig, N., Fischer, C., Frank, T., Garibaldi, L.A., Hermann, J., Herzog, F., Inclán, D., Jacot, K., Jauker, F., Jeanneret, P., Kaiser, M., Krauss, J., Le Féon, V., Marshall, J., Moonen, A., Moreno, G., Riedinger, V., Rundlöf, M., Rusch, A., Scheper, J., Schneider, G., Schüepp, C., Stutz, S., Sutter, L., Tamburini, G., Thies, C., Tormos, J., Tscharntke, T., Tschumi, M., Uzman, D., Wagner, C., Zubair-Anjum, M., Steffan-Dewenter, I., 2019. The interplay of landscape composition and configuration: new pathways to manage functional biodiversity and agroecosystem services across Europe. Ecol. Lett. 22, 1083-1094. doi:10.1111/ele.13265

Mazerolle, M.J., 2019. AICcmodavg: Model selection and multimodel inference based on (Q)AIC(c). R package version 2.2-2.

Meyer, C., 2012. Agroforestry: A study of farmer attitudes and perceptions in England. MSc thesis. University of Reading.

Newbold, T., Hudson, L.N., Hill, S.L.L., Contu, S., Lysenko, I., Senior, R.A., Börger, L., Bennett, D.J., Choimes, A., Collen, B., Day, J., De Palma, A., Díaz, S., Echeverria-Londoño, S., Edgar, M.J., Feldman, A., Garon, M., Harrison, M.L.K., Alhusseini, T., Ingram, D.J., Itescu, Y., Kattge, J., Kemp, V., Kirkpatrick, L., Kleyer, M., Correia, D.L.P., Martin, C.D., Meiri, S., Novosolov, M., Pan, Y., Phillips, H.R.P., Purves, D.W., Robinson, A., Simpson, J., Tuck, S.L., Weiher, E., White, H.J., Ewers, R.M., Mace, G.M., Scharlemann, J.P.W., Purvis, A., 2015. Global effects of land use on local terrestrial biodiversity. Nature 520, 45-50. doi:10.1038/nature14324

Nicholls, C., Altieri, M., 2013. Plant biodiversity enhances bees and other insect pollinators in agroecosystems. A review. Agron. Sustain. Dev. 33, 257-274. doi:10.1007/s13593-012-0092-y

Nicholson, C.C., Koh, I., Richardson, L.L., Beauchemin, A., Ricketts, T.H., 2017. Farm and landscape factors interact to affect the supply of pollination services. Agric. Ecosyst. Environ. 250, 113- 
880

881

882

883

884

885

886

887

888

889

890

891

892

893

894

895

896

897

898

899

900

901

902

O'Connor, R.S., Kunin, W.E., Garratt, M.P.D., Potts, S.G., Roy, H.E., Andrews, C., Jones, C.M., Peyton, J., Savage, J., Harvey, M., Morris, R.K.A., Roberts, S.P.M., Wright, I., Vanbergen, A.J., Carvell, C., 2019. Monitoring insect pollinators and flower visitation: the effectiveness and feasibility of different survey methods. Methods Ecol. Evol. 2041-210X.13292. doi:10.1111/2041210X.13292

Peng, R.K., Incoll, L.D., Sutton, S.L., Wright, C., Chadwick, A., 1993. Diversity of Airborne Arthropods in a Silvoarable Agroforestry System. J. Appl. Ecol. 30, 551-562.

Persson, A.S., Rundlof, M., Clough, Y., Smith, H.G., 2015. Bumble bees show trait-dependent vulnerability to landscape simplification. Biodivers. Conserv. 24, 3469-3489. doi:10.1007/s10531-015-1008-3

Ponisio, L.C., de Valpine, P., M'Gonigle, L.K., Kremen, C., 2019. Proximity of restored hedgerows interacts with local floral diversity and species' traits to shape long-term pollinator metacommunity dynamics. Ecol. Lett. 22, ele.13257. doi:10.1111/ele.13257

Potts, S.G., Biesmeijer, J.C., Kremen, C., Neumann, P., Schweiger, O., Kunin, W.E., 2010. Global pollinator declines: Trends, impacts and drivers. Trends Ecol. Evol. 25, 345-353. doi:10.1016/j.tree.2010.01.007

Potts, S.G., Imperatriz-Fonseca, V., Ngo, H.T., Aizen, M.A., Biesmeijer, J.C., Breeze, T.D., Dicks, L. V, Garibaldi, L.A., Hill, R., Settele, J., Vanbergen, A.J., 2016. Safeguarding pollinators and their values to human well-being. Nature 540, 220-229. doi:10.1038/nature20588

Potts, S.G., Woodcock, B.A., Roberts, S.P.M., Tscheulin, T., Pilgrim, E.S., Brown, V.K., Tallowin, J.R., 2009. Enhancing pollinator biodiversity in intensive grasslands. J. Appl. Ecol. 46, 369-379. doi:10.1111/j.1365-2664.2009.01609.x

Powney, G.D., Carvell, C., Edwards, M., Morris, R.K.A., Roy, H.E., Woodcock, B.A., Isaac, N.J.B., 2019. 
Widespread losses of pollinating insects in Britain. Nat. Commun. 10, 1018. doi:10.1038/s41467-019-08974-9

Pretty, J., Benton, T.G., Bharucha, Z.P., Dicks, L. V., Flora, C.B., Godfray, H.C.J., Goulson, D., Hartley, S., Lampkin, N., Morris, C., Pierzynski, G., Prasad, P.V.V., Reganold, J., Rockström, J., Smith, P., Thorne, P., Wratten, S., 2018. Global assessment of agricultural system redesign for sustainable intensification. Nat. Sustain. 1, 441-446. doi:10.1038/s41893-018-0114-0

Pumariño, L., Sileshi, G.W., Gripenberg, S., Kaartinen, R., Barrios, E., Muchane, M.N., Midega, C., Jonsson, M., 2015. Effects of agroforestry on pest, disease and weed control: A meta-analysis. Basic Appl. Ecol. 16, 573-582. doi:10.1016/j.baae.2015.08.006

R Development Core Team, 2019. R: A language and environment for statistical computing.

Ramsden, M.W., Menéndez, R., Leather, S.R., Wäckers, F., 2015. Optimizing field margins for biocontrol services: The relative role of aphid abundance, annual floral resources, and overwinter habitat in enhancing aphid natural enemies. Agric. Ecosyst. Environ. 199, 94-104. doi:10.1016/j.agee.2014.08.024

Ray, D.K., Ramankutty, N., Mueller, N.D., West, P.C., Foley, J.A., 2012. Recent patterns of crop yield growth and stagnation. Nat Commun 3, 1293. doi:http://www.nature.com/ncomms/journal/v3/n12/suppinfo/ncomms2296_S1.html

Rhodes, T.K., Aguilar, F.X., Jose, S., Gold, M., 2018. Factors influencing the adoption of riparian forest buffers in the Tuttle Creek Reservoir watershed of Kansas, USA. Agrofor. Syst. 92, 739757. doi:10.1007/s10457-016-0045-6

Rockström, J., Williams, J., Daily, G., Noble, A., Matthews, N., Gordon, L., Wetterstrand, H., DeClerck, F., Shah, M., Steduto, P., de Fraiture, C., Hatibu, N., Unver, O., Bird, J., Sibanda, L., Smith, J., 2017. Sustainable intensification of agriculture for human prosperity and global sustainability. Ambio 46, 4-17. doi:10.1007/s13280-016-0793-6 
Roulston, T.H., Goodell, K., 2011. The Role of Resources and Risks in Regulating Wild Bee Populations. Annu. Rev. Entomol. 56, 293-312. doi:10.1146/annurev-ento-120709-144802

Russo, L., Park, M., Gibbs, J., Danforth, B., 2015. The challenge of accurately documenting bee species richness in agroecosystems: bee diversity in eastern apple orchards. Ecol. Evol. 5, 3531-3540. doi:10.1002/ece3.1582

Sánchez-Bayo, F., Wyckhuys, K.A.G., 2019. Worldwide decline of the entomofauna: A review of its drivers. Biol. Conserv. 232, 8-27. doi:10.1016/J.BIOCON.2019.01.020

Scheper, J., Bommarco, R., Holzschuh, A., Potts, S.G., Riedinger, V., Roberts, S.P.M., Rundlöf, M., Smith, H.G., Steffan-Dewenter, I., Wickens, J.B., Wickens, V.J., Kleijn, D., 2015. Local and landscape-level floral resources explain effects of wildflower strips on wild bees across four European countries. J. Appl. Ecol. 52, 1165-1175. doi:10.1111/1365-2664.12479

Scheper, J., Holzschuh, A., Kuussaari, M., Potts, S.G., Rundlöf, M., Smith, H.G., Kleijn, D., 2013. Environmental factors driving the effectiveness of European agri-environmental measures in mitigating pollinator loss - a meta-analysis. Ecol. Lett. 16, 912-920. doi:10.1111/ele.12128

Scherber, C., Eisenhauer, N., Weisser, W.W., Schmid, B., Voigt, W., Fischer, M., Schulze, E.-D., Roscher, C., Weigelt, A., Allan, E., Beszler, H., Bonkowski, M., Buchmann, N., Buscot, F., Clement, L.W., Ebeling, A., Engels, C., Halle, S., Kertscher, I., Klein, A.-M., Koller, R., Konig, S., Kowalski, E., Kummer, V., Kuu, A., Lange, M., Lauterbach, D., Middelhoff, C., Migunova, V.D., Milcu, A., Muller, R., Partsch, S., Petermann, J.S., Renker, C., Rottstock, T., Sabais, A., Scheu, S., Schumacher, J., Temperton, V.M., Tscharntke, T., 2010. Bottom-up effects of plant diversity on multitrophic interactions in a biodiversity experiment. Nature 468, 553-556. doi:http://www.nature.com/nature/journal/v468/n7323/abs/nature09492.html\#supplement ary-information

Seifan, M., Hoch, E.M., Hanoteaux, S., Tielbörger, K., 2014. The outcome of shared pollination services is affected by the density and spatial pattern of an attractive neighbour. J. Ecol. 102, 
953

954

955

956

957

958

959

960

961

962

963

964

965

966

967

968

969

970

971

972

973

974

975

Sereke, F., Graves, A.R., Dux, D., Palma, J.H.N., Herzog, F., 2015. Innovative agroecosystem goods and services: key profitability drivers in Swiss agroforestry. Agron. Sustain. Dev. 35, 759-770. doi:10.1007/s13593-014-0261-2

Smith, J., Pearce, B.D., Wolfe, M.S., 2012. A European perspective for developing modern multifunctional agroforestry systems for sustainable intensification. Renew. Agric. Food Syst. 27, 323-332. doi:10.1017/S1742170511000597

Smith, P., Ashmore, M., Black, H., Burgess, P., Evans, C., Hails, R., Potts, S.G., Thomson, A., Quine, T., Biesmeijer, K., Breeze, T., Broadmeadow, M., Ferrier, R., Freer, J., Hansom, J., Haygarth, P., Hesketh, H., Hicks, K., Johnson, A., Kay, D., Kunin, W., Lilly, A., May, L., Memmott, J., Orr, H., Pickup, R., Purse, B., Squire, G., 2011. Regulating services [chapter 14], in: UK National Ecosystem Assessment. Understanding Nature's Value to Society. Technical Report. UNEPWCMC, Cambridge, UK, pp. 535-596.

Staton, T., Walters, R.J., Smith, J., Girling, R.D., 2019. Evaluating the effects of integrating trees into temperate arable systems on pest control and pollination. Agric. Syst. 176, 102676. doi:10.1016/j.agsy.2019.102676

Sutter, L., Jeanneret, P., Bartual, A.M., Bocci, G., Albrecht, M., 2017. Enhancing plant diversity in agricultural landscapes promotes both rare bees and dominant crop-pollinating bees through complementary increase in key floral resources. J. Appl. Ecol. doi:10.1111/1365-2664.12907

Symonds, M.R.E., Moussalli, A., 2011. A brief guide to model selection, multimodel inference and model averaging in behavioural ecology using Akaike's information criterion. Behav. Ecol. Sociobiol. 65, 13-21. doi:10.1007/s00265-010-1037-6

Valdivia, C., Barbieri, C., Gold, M.A., 2012. Between Forestry and Farming: Policy and Environmental Implications of the Barriers to Agroforestry Adoption. Can. J. Agric. Econ. Can. d'agroeconomie 
977

978

979

980

981

982

983

984

985

986

987

988

989

990

991

992

993

994

995

996

997

998

999

Vanbergen, A.J., Hails, R.S., Watt, A.D., Jones, T.H., 2006. Consequences for host-parasitoid interactions of grazing-dependent habitat heterogeneity. J. Anim. Ecol. 75, 789-801. doi:10.1111/j.1365-2656.2006.01099.x

Vanbergen, A.J., the IPI, 2013. Threats to an ecosystem service: pressures on pollinators. Front. Ecol. Environ. 11, 251-259. doi:10.1890/120126

Vanbergen, A.J., Woodcock, B.A., Gray, A., Grant, F., Telford, A., Lambdon, P., Chapman, D.S., Pywell, R.F., Heard, M.S., Cavers, S., 2014. Grazing alters insect visitation networks and plant mating systems. Funct. Ecol. 28, 178-189. doi:10.1111/1365-2435.12191

Vandermeer, J., Perfecto, I., 2007. The agricultural matrix and a future paradigm for conservation. Conserv. Biol. 21, 274-277. doi:DOI: 10.1111/j.1523-1739.2006.00582.x

Varah, A., Jones, H., Smith, J., Potts, S.G., 2013. Enhanced biodiversity and pollination in UK agroforestry systems. J. Sci. Food Agric. 93, 2073-2075. doi:10.1002/jsfa.6148

Winfree, R., Reilly, J.R., Bartomeus, I., Cariveau, D.P., Williams, N.M., Gibbs, J., 2018. Species turnover promotes the importance of bee diversity for crop pollination at regional scales. Science (80-. ). 359, 791-793. doi:10.1126/SCIENCE.AAO2117

Winfree, R., W. Fox, J., Williams, N.M., Reilly, J.R., Cariveau, D.P., 2015. Abundance of common species, not species richness, drives delivery of a real-world ecosystem service. Ecol. Lett. 18, 626-635. doi:10.1111/ele.12424

Woodcock, B.A., Garratt, M.P.D., Powney, G.D., Shaw, R.F., Osborne, J.L., Soroka, J., Lindström, S.A.M., Stanley, D., Ouvrard, P., Edwards, M.E., Jauker, F., McCracken, M.E., Zou, Y., Potts, S.G., Rundlöf, M., Noriega, J.A., Greenop, A., Smith, H.G., Bommarco, R., van der Werf, W., Stout, J.C., Steffan-Dewenter, I., Morandin, L., Bullock, J.M., Pywell, R.F., 2019. Meta-analysis reveals that pollinator functional diversity and abundance enhance crop pollination and yield. 
1001 Woodcock, T.S., Pekkola, L.J., Dawson, C., Gadallah, F.L., Kevan, P.G., 2014. Development of a 1002 Pollination Service Measurement (PSM) method using potted plant phytometry. Environ. Monit. Assess. 186, 5041-5057. doi:10.1007/s10661-014-3758-x

1004 Zurbuchen, A., Landert, L., Klaiber, J., Müller, A., Hein, S., Dorn, S., 2010. Maximum foraging ranges 1005 in solitary bees: only few individuals have the capability to cover long foraging distances. Biol. Conserv. 143, 669-676. doi:10.1016/J.BIOCON.2009.12.003 
(a)

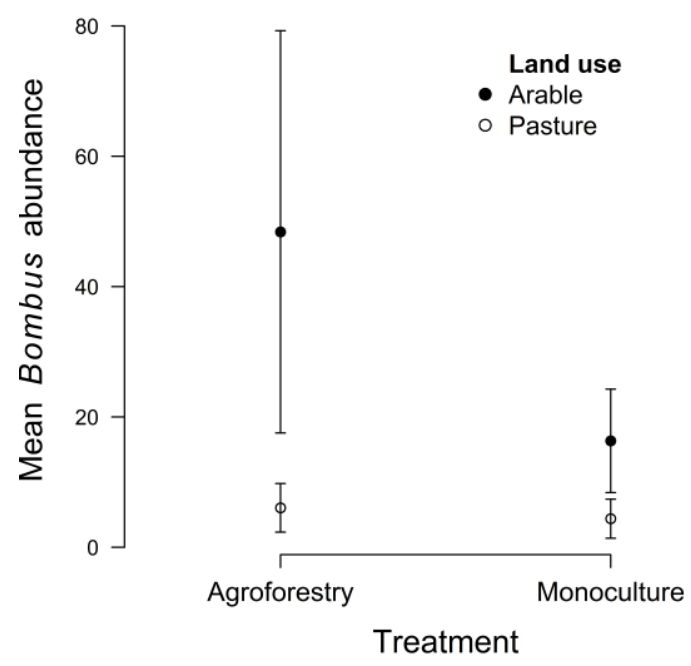

(c)

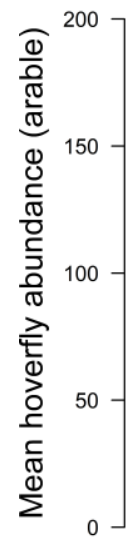

1009

1010

1011

1012

1013

1014

1015

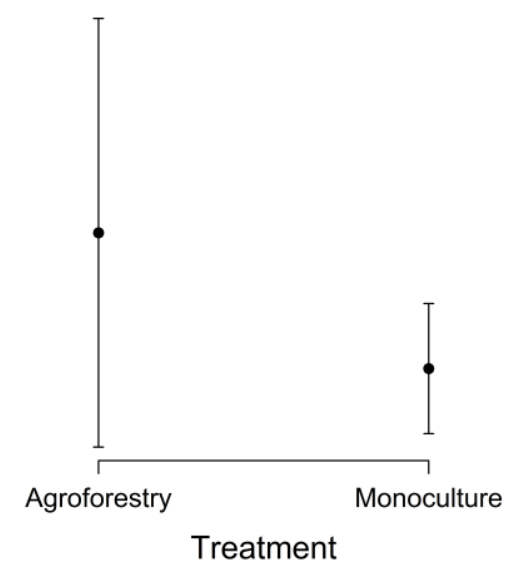

(b)

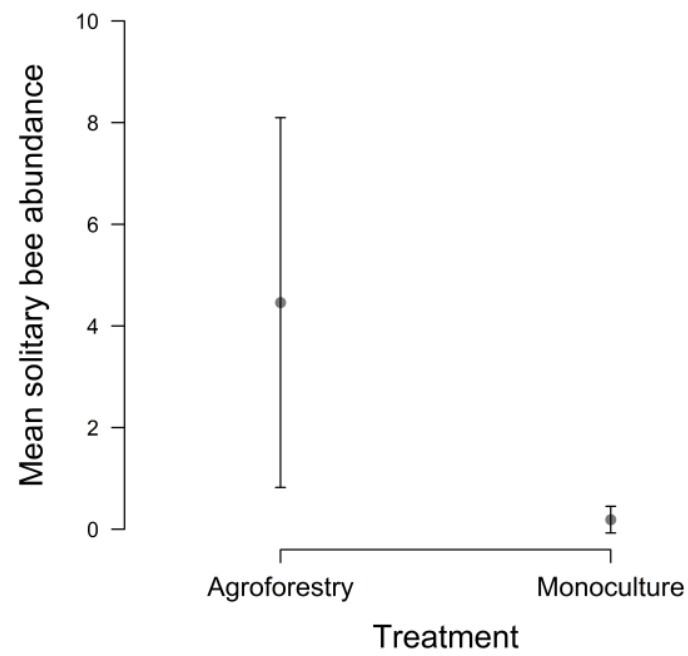

(d)

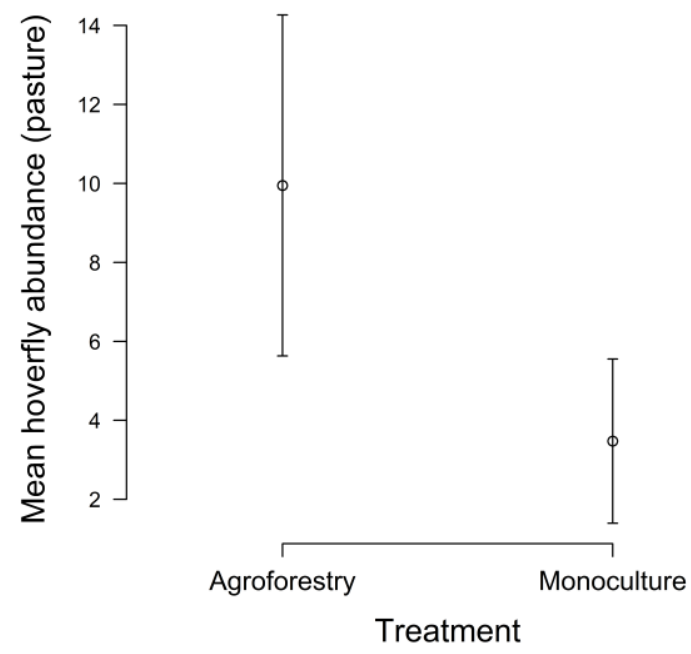

Figure 1 Abundance of wild pollinating insects from transect data.

= arable land; $\bigcirc$ = pastureland; $\bigcirc$ = both land use types. (a) Mean bumblebee abundance and 95\% Cls; (b) Mean solitary bee abundance and 95\% Cls; (c) and (d) hoverfly abundance was much higher in arable than pasture systems and these are therefore shown separately: (c) mean hoverfly abundance and 95\% Cls, arable systems (figure shows mean abundance across both arable sites, hence the overlapping confidence intervals; however, model output shows strong evidence 


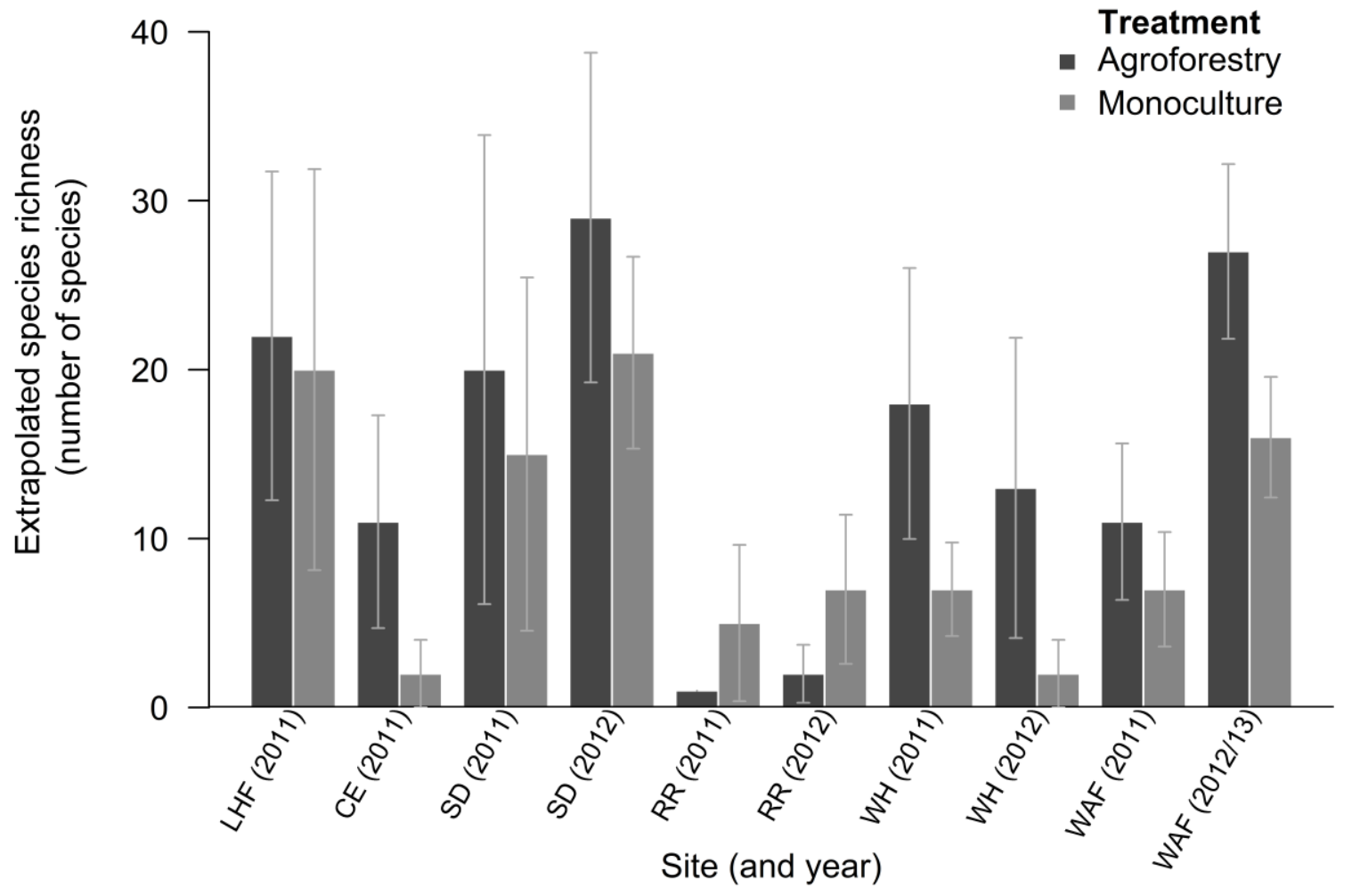

1018 Figure 2 Species richness (extrapolated to 14 samples) of solitary bees at each site. Bars show 95\% confidence 1019 intervals. For site details see Table A.1.

1020 


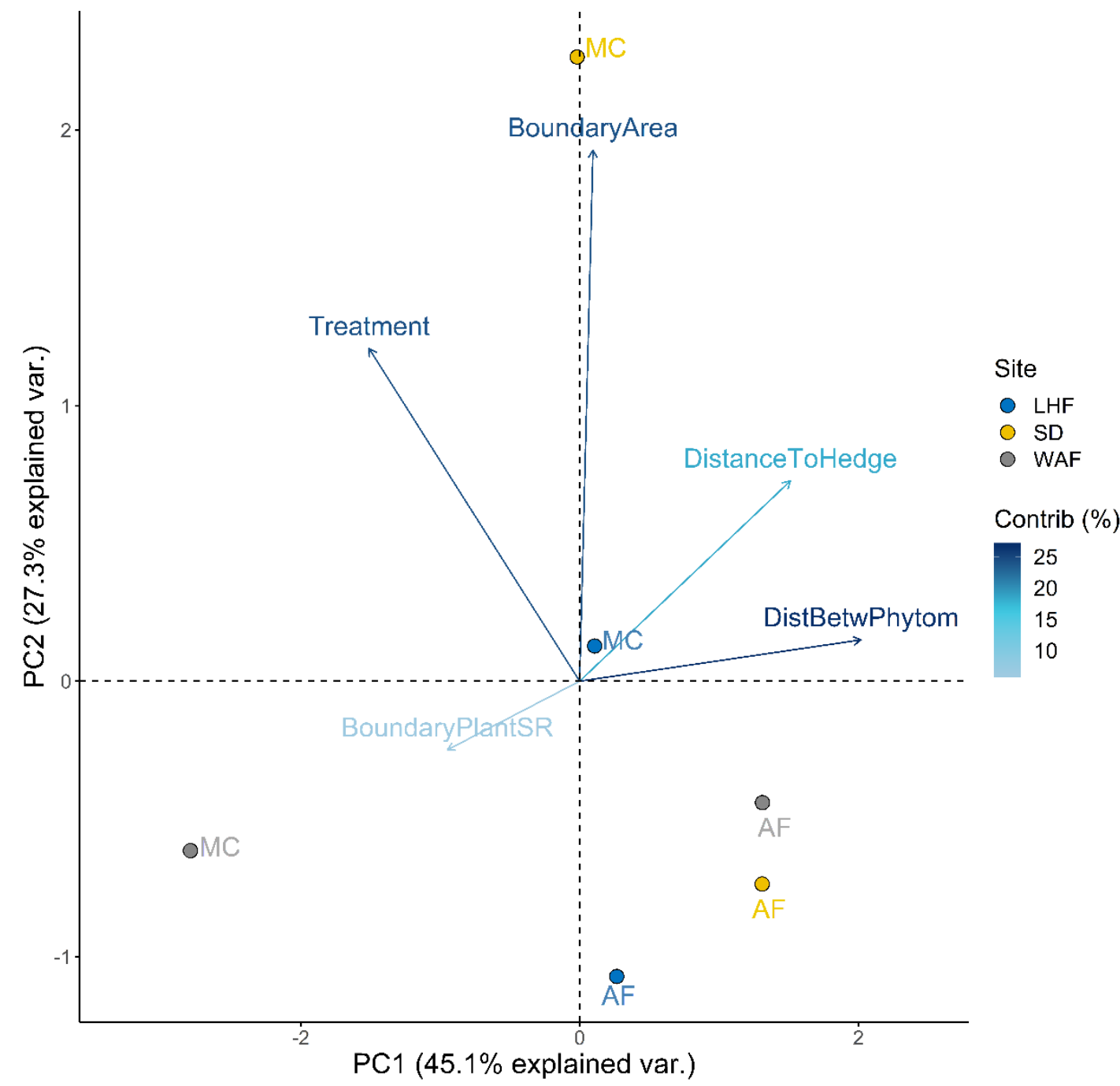

Figure 3 PCA loading plot of 2013 phytometer data. Variables are coloured according to their total contribution (\%) to PC1 and PC2 combined. Variable names as follows: tmt, treatment; bound.area = total uncropped area (i.e. hedgerows, field margins) around field; hedg. dist = distance from the transect to the nearest boundary hedgerow; distbetw = the shortest (diagonal) distance between phytometer plants; ipBSR = species richness of insect-pollinated plants in field boundary. 
Table 1 ABUNDANCE. Model-averaged parameter estimates from models relating wild pollinating insect abundance to environmental variables. For each pollinator group, regression coefficients $(\beta$, standardized at SD $=0.5)$ are averages of $\beta_{i}$ across all models in the top model set, weighted by the Akaike weight $w_{i}$ of each model in the top model set (Burnham and Anderson, 2002).$w_{i}$ best $=$ Akaike weight of the best model from each top model subset. Calculations for $\beta$ only include $\beta_{i}$ from models in which a given parameter appears (natural average method). Values in brackets are $95 \%$ confidence intervals. Relative variable importance $\left(w_{i p}\right)$ is the sum of $w_{i}$ across all models including that variable (Burnham \& Anderson 2002). Variables with the greatest importance for each pollinator group have $w_{i p}$ in bold. NA indicates that the corresponding parameter was not included in any of the top models for that pollinator group. For details of all models in each top model set, see Appendix B.

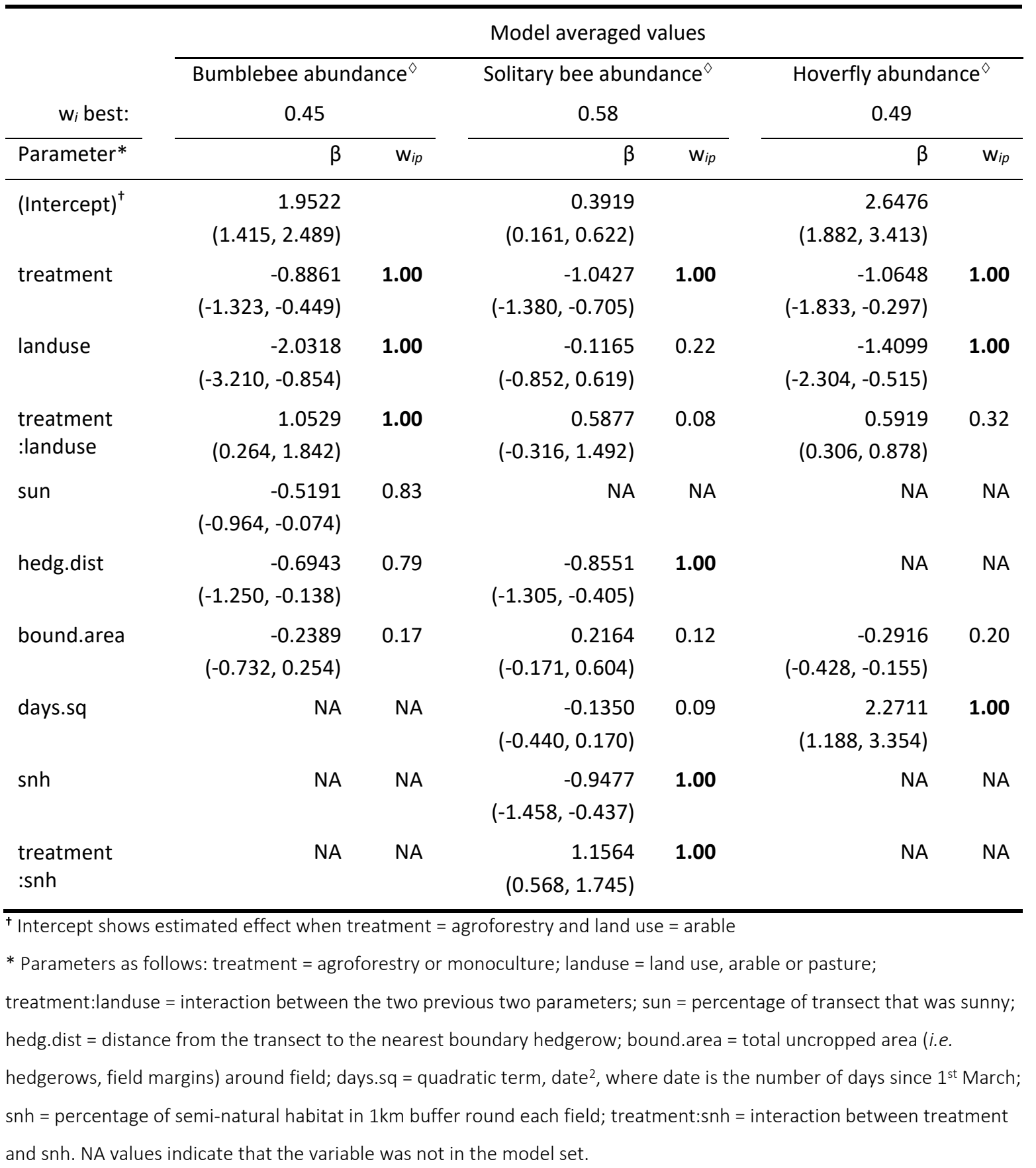


$\diamond$ Bumblebee and hoverfly transect data is from 5 sites in 2011, 4 sites in 2012 and 1 site in 2013 (6 sites across all years); solitary bee transect data is from 6 sites in 2011, 4 sites in 2012 and 1 site in 2013 (6 sites across all years). See Table A.3 for site-by-year data collection details.

Table 2 SPECIES RICHNESS. Model-averaged parameter estimates from models relating bumblebee species richness and square

Table 1. For details of all models in each top model set, see Appendix B.

\begin{tabular}{|c|c|c|c|c|}
\hline \multirow[b]{3}{*}{$w_{i}$ best: } & \multicolumn{4}{|c|}{ Model averaged values } \\
\hline & \multirow{2}{*}{\multicolumn{2}{|c|}{$\begin{array}{c}\text { Bumblebee } \\
\text { species richness } \\
0.35\end{array}$}} & \multirow{2}{*}{\multicolumn{2}{|c|}{$\begin{array}{c}\text { Solitary bee } \\
\text { species richness }^{\diamond} \\
0.30\end{array}$}} \\
\hline & & & & \\
\hline Parameter* & $\beta$ & Wip & $\beta$ & Wip \\
\hline \multirow[t]{2}{*}{$(\text { Intercept })^{\dagger}$} & 0.9474 & & 3.3742 & \\
\hline & $(0.646,1.249)$ & & $(2.633,4.115)$ & \\
\hline \multirow[t]{2}{*}{ treatment } & NA & NA & -0.6806 & 0.27 \\
\hline & & & $(-1.416,0.055)$ & \\
\hline \multirow[t]{2}{*}{ n.hedg.bound } & 0.5276 & 0.51 & 1.3360 & 0.15 \\
\hline & $(-0.021,1.077)$ & & $(0.300,2.372)$ & \\
\hline \multirow[t]{2}{*}{ hedg.dist } & NA & NA & 1.1926 & 0.31 \\
\hline & & & $(-0.081,2.467)$ & \\
\hline \multirow[t]{2}{*}{ snh } & NA & NA & -0.9001 & 0.13 \\
\hline & & & $(-2.289,0.489)$ & \\
\hline \multirow[t]{2}{*}{ bound.area } & -0.3945 & 0.30 & NA & NA \\
\hline & $(-1.069,0.280)$ & & & \\
\hline
\end{tabular}

$1051 \quad$ †* Footnotes as for Table 1, with the addition of $n$.hedg.bound = number of hedged boundaries around field.

$1052 \diamond$ Bumblebee pan trap data is from 5 sites in 2011, 4 sites in 2012 and 1 site in 2013 (6 sites across all years); solitary bee 1053 pan trap data is from 6 sites in 2011, 4 sites in 2012 and 1 site in 2013 ( 6 sites across all years). See Table A.4 for site-byyear data collection details. 

table see legend for Table 1. For details of all models in the top model set, see Appendix B.

\begin{tabular}{|c|c|c|}
\hline \multirow{4}{*}{$\begin{array}{l}\text { W }_{i} \text { best: } \\
\text { Parameter* }\end{array}$} & \multicolumn{2}{|c|}{ Model averaged values } \\
\hline & \multicolumn{2}{|c|}{ Seed count $2012^{\diamond}$} \\
\hline & \multicolumn{2}{|l|}{0.68} \\
\hline & $\beta$ & $W_{i p}$ \\
\hline \multirow[t]{2}{*}{ 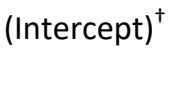 } & -0.1088 & \\
\hline & $(-0.666,0.448)$ & \\
\hline \multirow[t]{2}{*}{ treatment } & -1.7241 & 1.00 \\
\hline & $(-2.530,-0.918)$ & \\
\hline \multirow[t]{2}{*}{ hedg.dist } & -1.8241 & 1.00 \\
\hline & $(-2.908,-0.740)$ & \\
\hline \multirow[t]{2}{*}{ bound.area } & -0.4663 & 0.32 \\
\hline & $(-1.313,0.381)$ & \\
\hline
\end{tabular}

1058

†* Footnotes as for Tables $1 \& 2$.

$1059 \diamond$ Seed count is average number of seeds per fruit. 2012 phytometer data is from 1 pasture and 2 arable sites. 
Table 4 Summary of analyses in which there was strong evidence of a treatment effect.

\begin{tabular}{|c|c|c|c|c|}
\hline Taxon or dataset ${ }^{\ddagger}$ & Metric & Result $^{\dagger}$ & $\begin{array}{l}\text { Magnitude } \\
\text { of result }^{\Delta}\end{array}$ & Land use ${ }^{*}$ \\
\hline Bumblebees & abundance & $A F>M C$ & 2.4 & a \\
\hline Hoverflies & abundance & $A F>M C$ & 2.0 & $a, p$ \\
\hline Solitary bees & abundance & $A F>M C$ & 2.0 & $a, p$ \\
\hline Solitary bees & species richness & $\begin{array}{l}\mathrm{AF}>\mathrm{MC} \text { at } 40 \% \text { of site- } \\
\text { by-year samples }\end{array}$ & 10.5 & $a, p$ \\
\hline Solitary bees \& plants & species richness correlation & + & NA & $a, p$ \\
\hline $\begin{array}{l}\text { phytometer data, } \\
2012\end{array}$ & seed set & $A F>M C$ & 4.5 & $a, p$ \\
\hline
\end{tabular}

$1061 \ddagger$ All pollinator taxa were sampled in both 2011 and 2012. Plant species richness was sampled in the first year that data

1062 collection was carried out in a field.

$1063+$ Result shows direction of relationship between AF (agroforestry) and MC (monoculture) treatments, or direction of

1064 correlation (+ = positive).

$1065 \Delta$ Magnitude indicates effect size, or how many times higher one value was than the other: i.e. bumblebee abundance was

10662.4 times higher in AF treatments than MC treatments (in arable land). The value for solitary bee species richness is the

1067 average magnitude across instances where SR was significantly higher.

1068 *Column indicates in which type of land use the result was found: $a=$ arable, $p=$ pasture. 